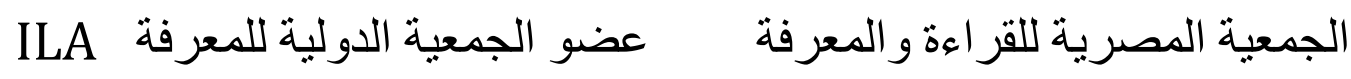

\title{
المنهج الجدلي وإمكان المعرفة في فلسفة أفلاطون
}

\author{
إعداد
}

أ / محمد سمير محمد عبد الحميد

المعيد بقسم الفلسفة والاجتماع

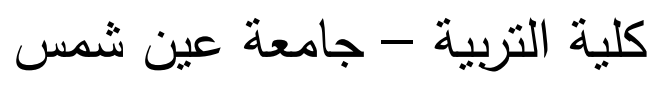

إثبراف

أ. أد / مراد وهبة جبران 


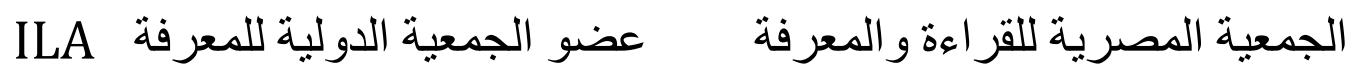




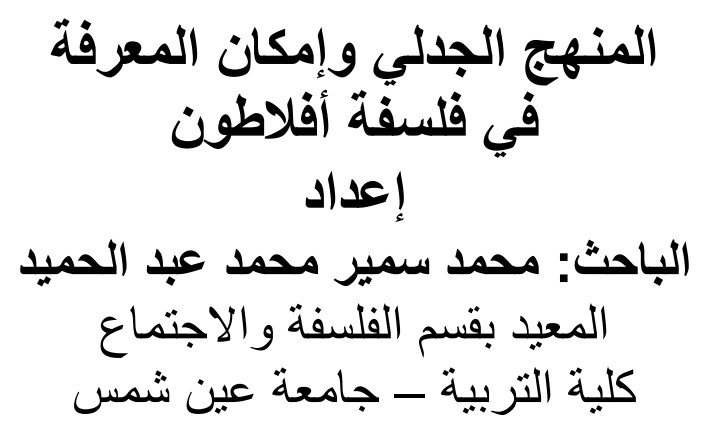

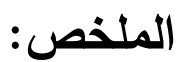

ينحصر موضوع البحث في دراسة نظرية المعرفة عند أفلاطون، تلك النظرية التي تبحث في المقام الأول عن الحقيقة المُطلقة وعن الكيفية التي يمكن أن تكون بها موضوعًا للفهم والإدراك البشرى. وبإمعان النظر في جملة محاورات أفلاطون نجد أن نظريته عن الن النه المعرفة لم تتخذ صورة كاملة ولم تُطرح بطريقة مباشرة في أي محاورة على حدى، وإنما كانت تتطور وتتعدل بشكل تدريجي عبر المحاورات. ويمكن التمبيز، داخل نظرية المعرفة الأفلاطونية، بين جانبين رئيسيين أحدهما سلبي والآخر إيجابي: ويتمثل الجانب السلبي في الانتقادات التي وجهها أفلاطون إلى نظريات المعرفة التقليدية الثائعة سواء السابقة عليه أو المعاصرة له. ويمكن القول بأن أفلاطون قد اله

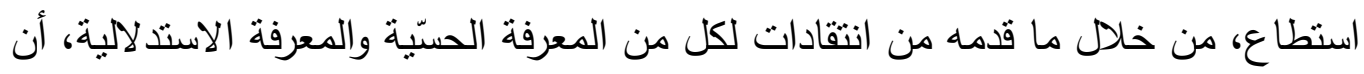
يحدد بوضوح ما هو (ليس بعلم أو بمعرفة)، وذلك كمرحلة تمهيدية لبناء نظريته الخاصة عما هو (علم ومعرفة بحقّ).

أما الجانب الإيجابي فقد تمنل في بناء أفلاطون لنظريته الخاصة عن المعرفة، والتي تقوم على أساس التمييز بين نوعين أساسيين من المعرفة(")، هما: ( المعرفة الحقيقية

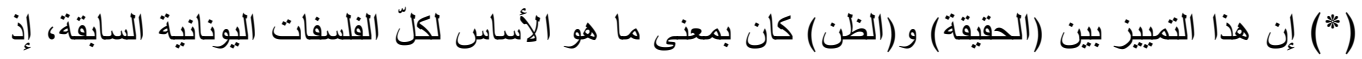

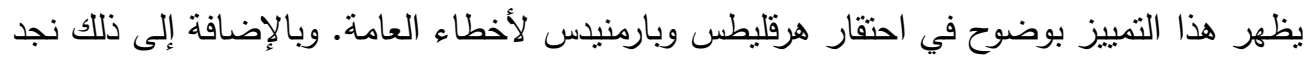

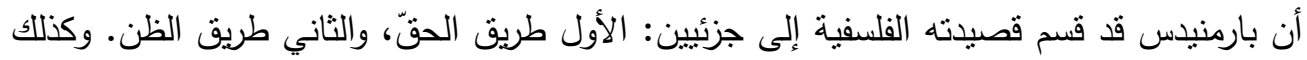


اليقينية) وموضوعها الدفاهيم والمبادئ الكلّيّة والمُطلقة والئفارقة لكلّ ما هو مادي وحسّي

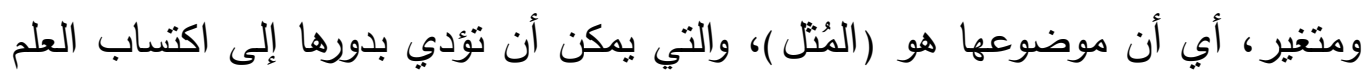

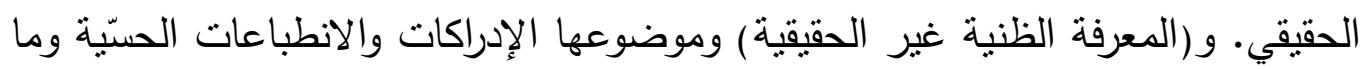

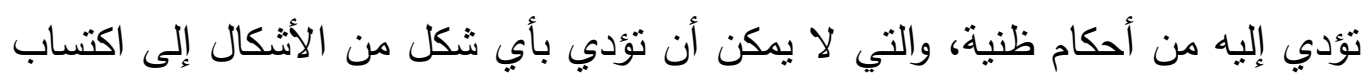

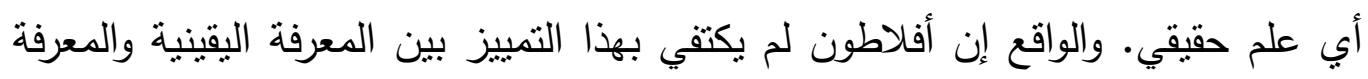

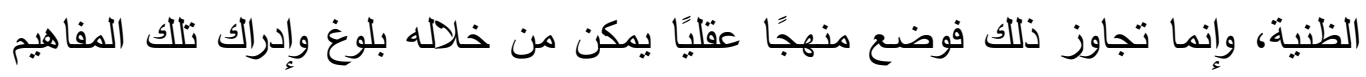

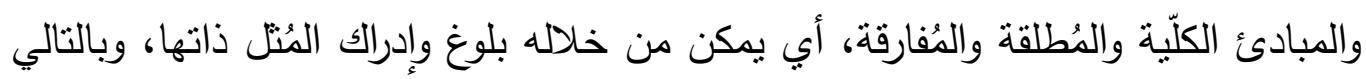
يُكَّن العقل البشري من اكتساب العلم الحقيقي والمعرفة اليقينية، وكان هذا المنهج العقلي هو (الجدل أو الديالكتيك).

\section{The Dialectical Method And The Possibility Of Knowledge In Plato's Philosophy Mohamed Samir Mohamed Abd Elhamid}

Demonstrator, Department Of Philosophy And Sociology Faculty Of Education - Ain Shams University

\section{Abstract:}

The research subject is consisted in studying Plato's theory of knowledge, which searches primarily for absolute truth and how it can be a subject of human understanding and perception. A closer look at Plato's dialogues, we find that his theory of knowledge was not presented directly in any one of the dialogues separately, but rather developed and modified gradually through the dialogues. It can also distinguish, within his theory of knowledge, between two main aspects one negative and the other positive:

ميز ديموقريطس بين المعرفة الخالصة والمعرفة الغامضة. ومن هنا كانت هذه النظريات بمثابة المصدر الممهد لنظرية أفلاطون عن المعرفة لمبنة

Look: Ritchie, David George: Plato, New York, Charles Scribner's Sons, 1902.

Chapter: IV, P: 81. 
The negative aspect was represented in Plato's criticisms of the traditional theories of knowledge, whether previous or contemporary to him. It can be said that Plato was able, through his criticisms of both sensible and inferential knowledge, to clearly define what is "not true knowledge", as a preliminary phase to build his own theory of what is "true knowledge". And Plato devoted "Theaetetus" to this critical negative aspect of his theory of knowledge.

The positive aspect was represented in Plato's building of his own theory of knowledge, which is based on the distinction between two basic types of knowledge, which are: "The certain knowledge" and its object is universal, absolute and transcendent concepts and principles of everything that is material, sensible and changing, that is, its subject is "the Ideas" which in turn can lead to the acquisition of the true knowledge. "The uncertain knowledge" and its subject is sensible perceptions which in turn lead to uncertain judgments, and therefore It cannot lead in any way to the acquisition of any true knowledge. Indeed, Plato did not stop at the distinction between the certain knowledge and the uncertain knowledge, but rather went beyond that, so he developed a rational method which through it the human mind can be able to realize the universal, absolute and transcendent concepts and principles. It is possible through this method to realize "the Ideas" itself, Thus this method enables the human mind to acquire the true knowledge, and this method was "The Dialectical Method". It can be said that Plato almost presented this positive aspect of his theory of knowledge in all his dialogues, and at the forefront of those dialogues "The Republic", "Phaedrus" and "Meno". 


\section{المنهج الجدلي و إمكان المعرفة في فلسفة أفلاطون الباحث: محمد سمير محمد عبد الحميا}

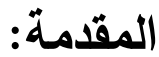

لقد أكد أفلاطون (") 427 - 347ق •م) في مجمل محاوراته على رفضه التام لفكرة نسبية الحقيقة، إذ إن ذلك سيؤدى بالضرورة إلى عدم وجود أي معيار أو قاعدة ثابتة،

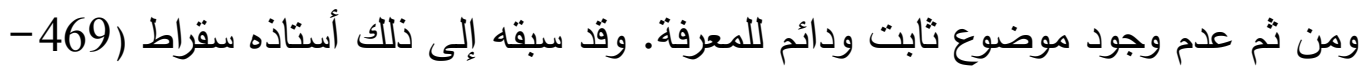

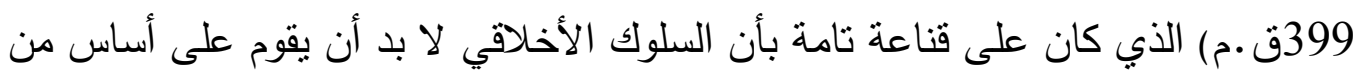

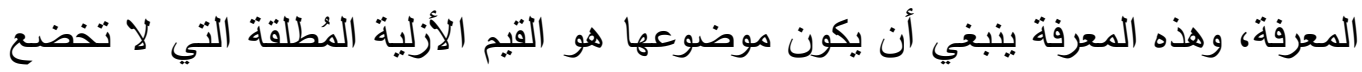

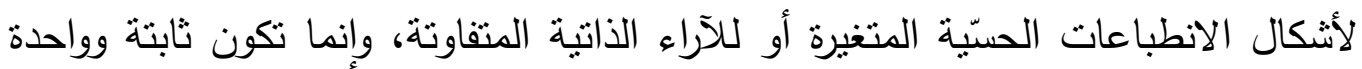

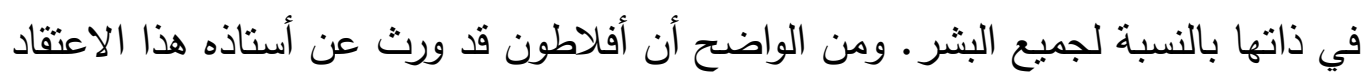

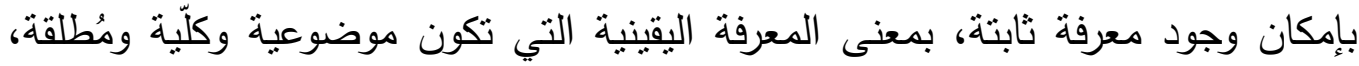

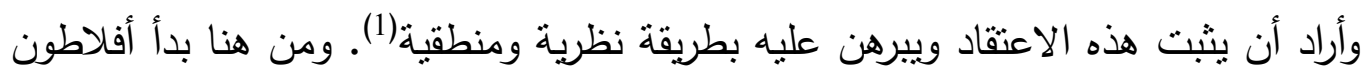

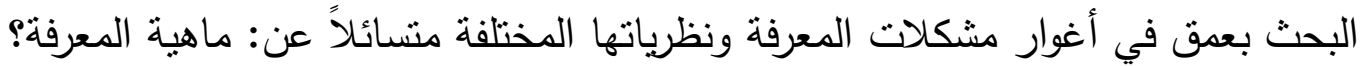
وماهية موضوعها؟

\section{أولاً: ماهية المعرفة وماهية موضوعها:}

ذهب أفلاطون إلى أن المعرفة اليقينية الوحيدة والممكنة إنما هي تلك المعرفة التي

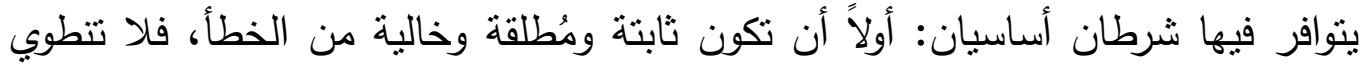
على أي خلط أو تضليل، وثانيًا أن تكون عما هو موجود، أي عما هو واقعي وحقيقي.

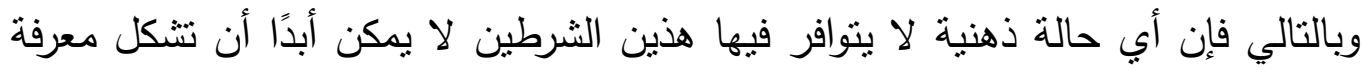

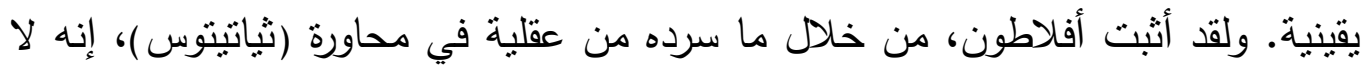
المعرفة الحسّية ولا المعرفة الاستدلالية تملك أي من هذين الثرطين الأساسيين ومن ثم

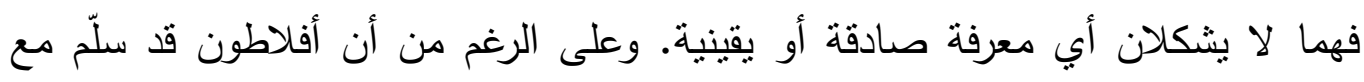
476 
بروتاغوراس (480-410ق •م) على القول بنسبية الإدراك الحتّي، إلا إنه لم يقبل بتعميم

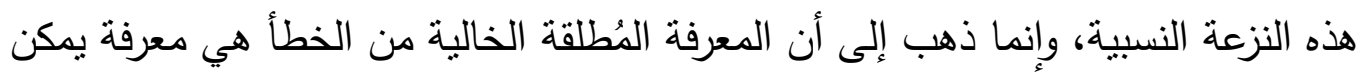

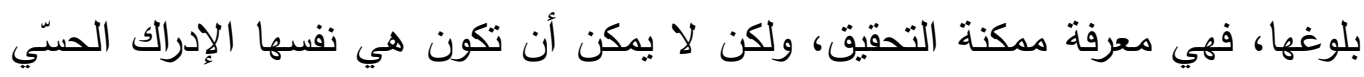

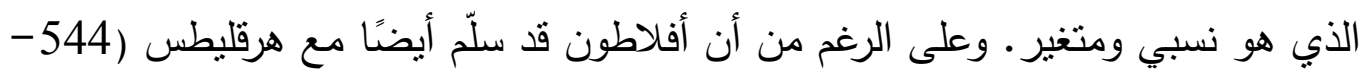

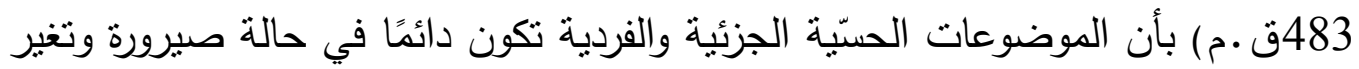

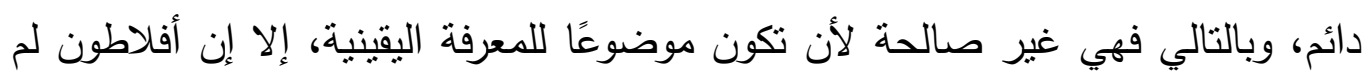

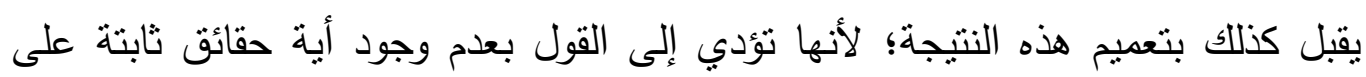

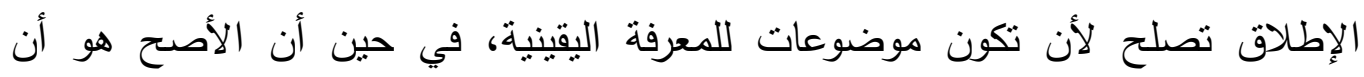

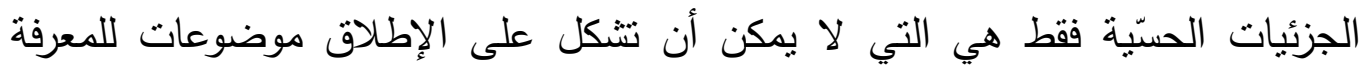
اليقينية. أما موضوعات المعرفة اليقينية فلا بد أن تثكل في ذاتها لتها حقائق ثابتة ودائمة الإنة

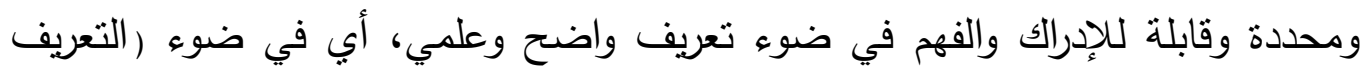
الكلّي) على نحو ما ارتأى سقراط (2).

والسؤال هنا: ما هو الموضوع الحققي للمعرفة اليقينية في نظر أفلاطون؟

\section{( أ ) الموضوع الحقيقي للمعرفة اليقينية:}

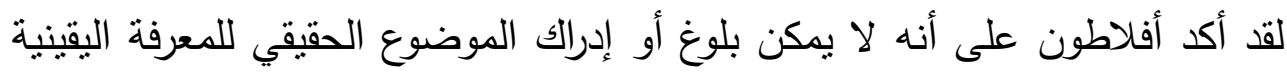

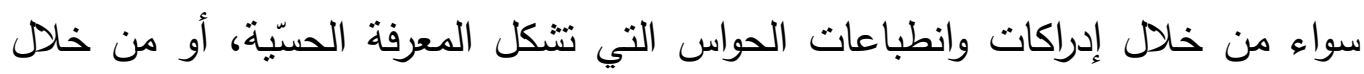

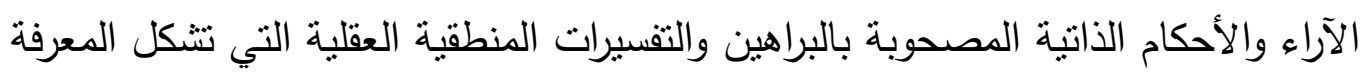

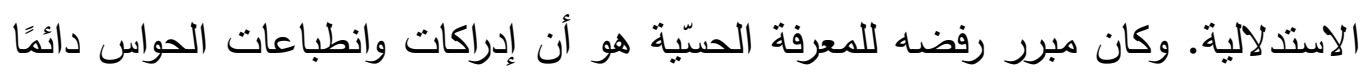

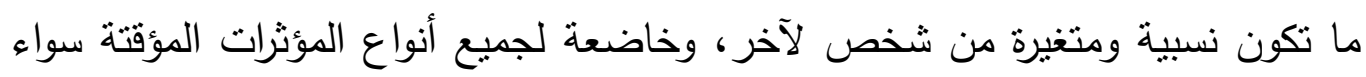

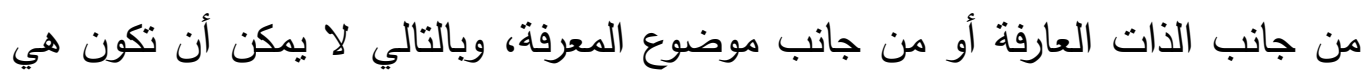

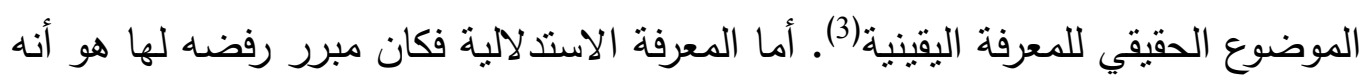

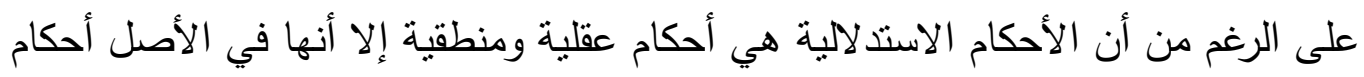


مبنية على فروض متعلقة بالعالم المحسوس وبأنثيائه المادية النسبية المتغيرة، وبالتالي فإن

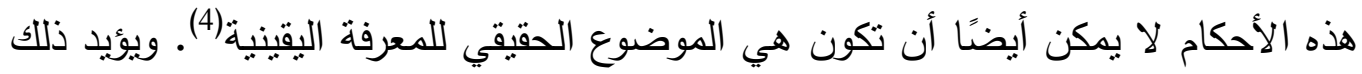

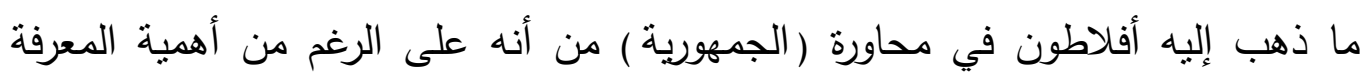

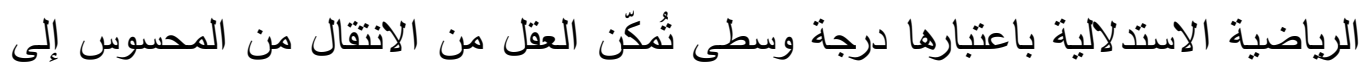

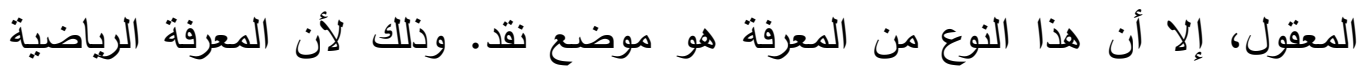

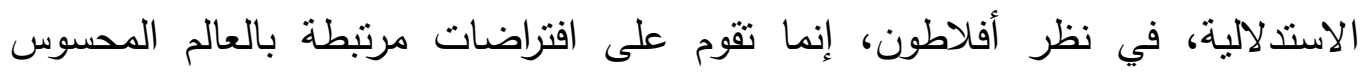

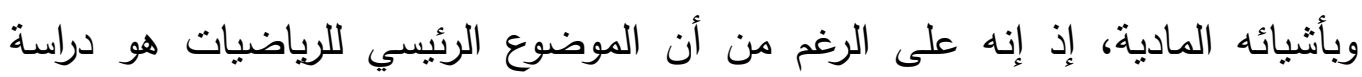

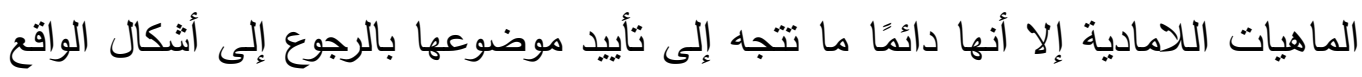
المحسوس. وفي ذلك يقول أفلاطون على لسان سقراط موجهًا الحديث إلى جلوكون:

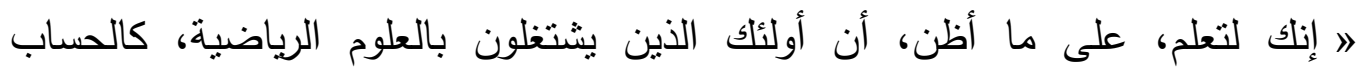

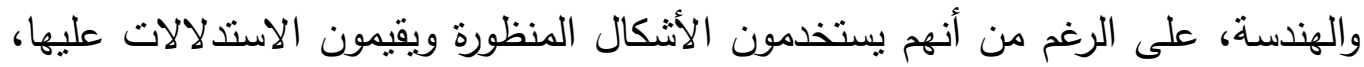
إلا أن تفكيرهم لا ينصب على هذه الأثنكال ذاتها، وإنما ينصب تفكيرهم على المُنتل العليا

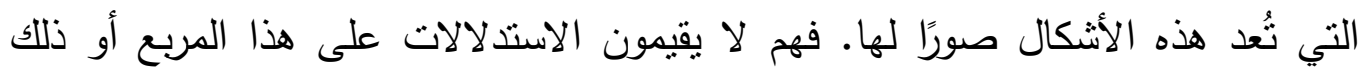

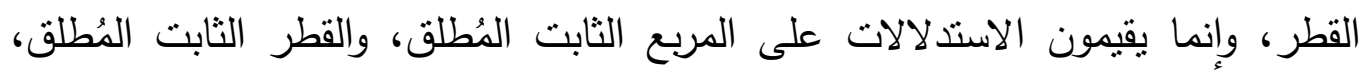
وكنلك الحال في باقي الأشكال المختلفة الأخرى. وهكذا فإن الأنثال التهال التي يرسمونها

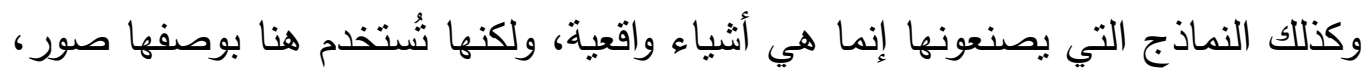

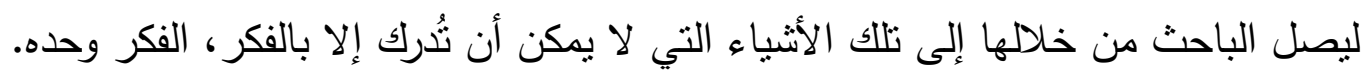

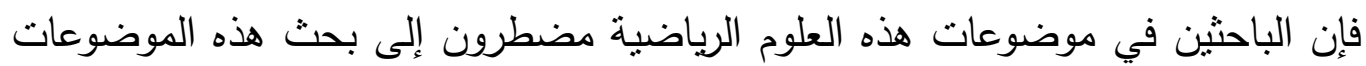
بالفكر وليس بالحواس، ولكن بسبب أنهم ييحثون هذه الموضوعات ابتداء من الفرضيات

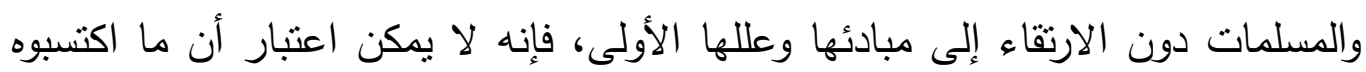
هو معرفة حقيقية بهذه الموضوعاته| (5). 
وبإمعان النظر في تلك الأحكام التي من اليُفترض إنه لا يمكن الوصول إليها إلا

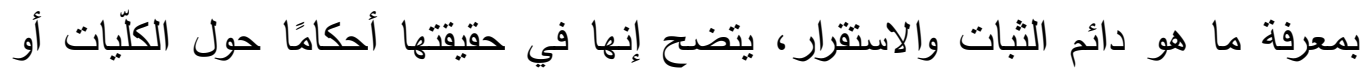

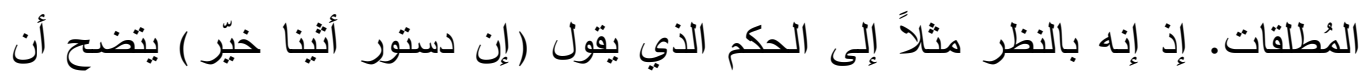

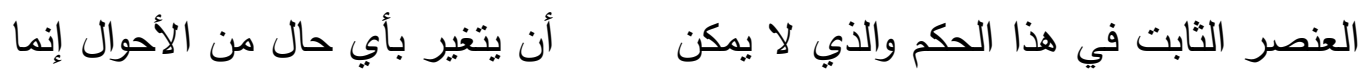

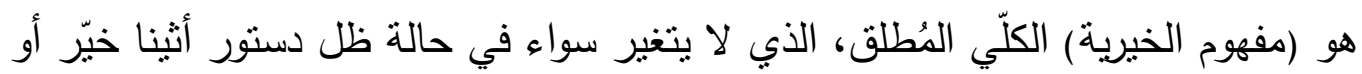

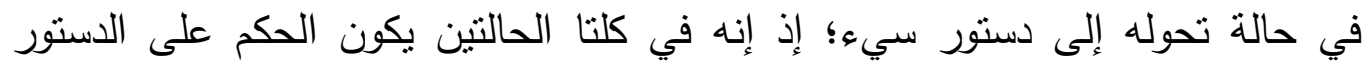

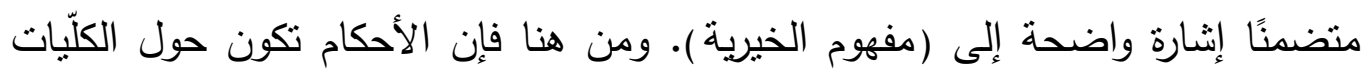

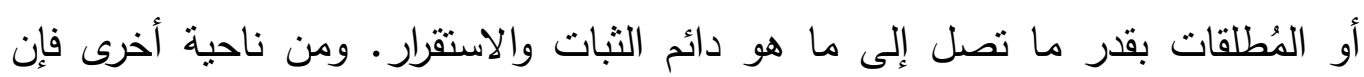

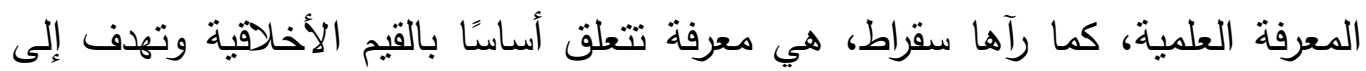

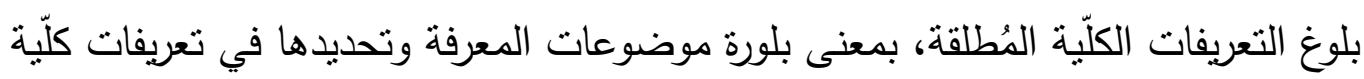

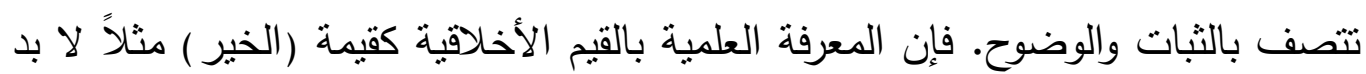

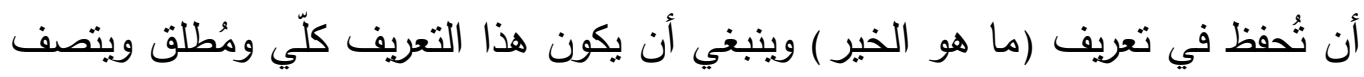

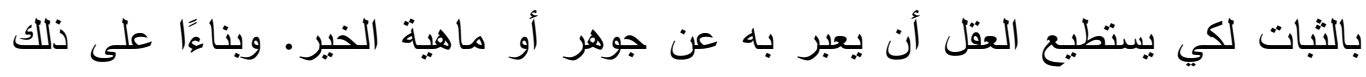

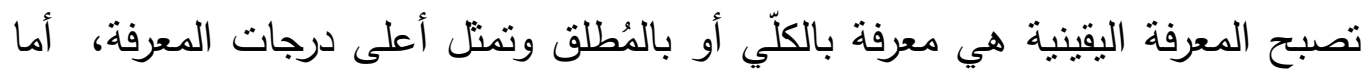

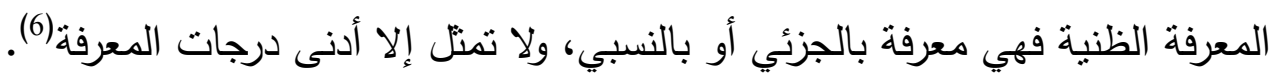

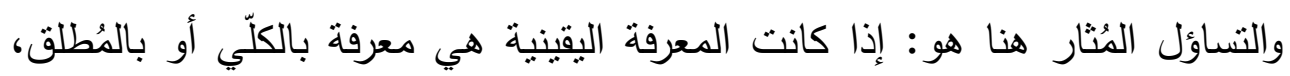

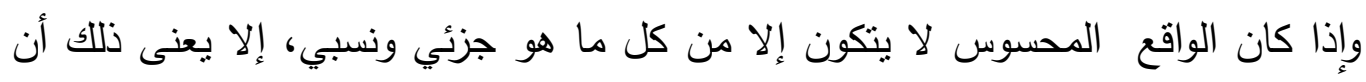

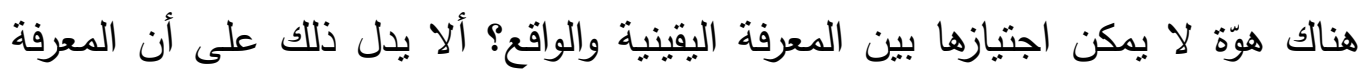

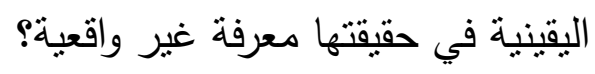

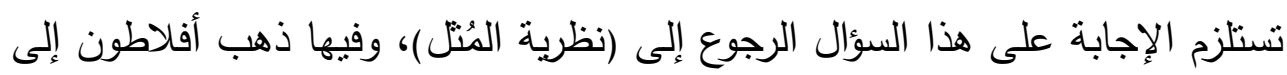

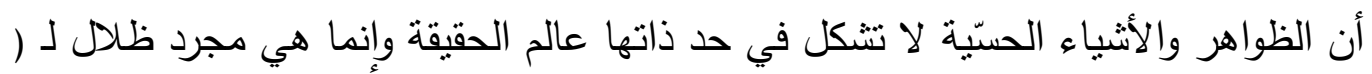

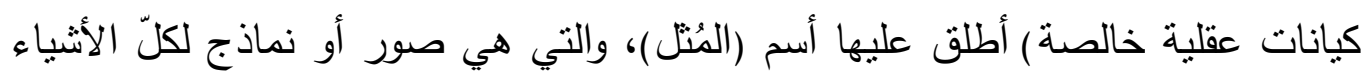




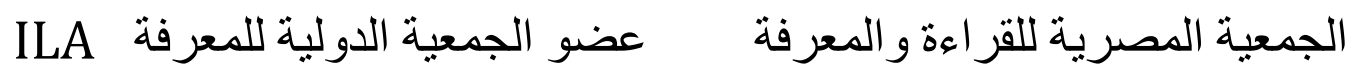

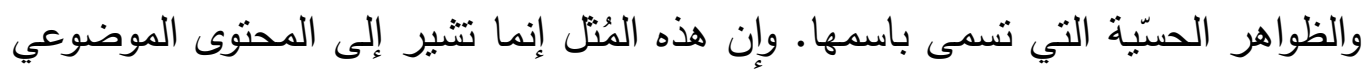

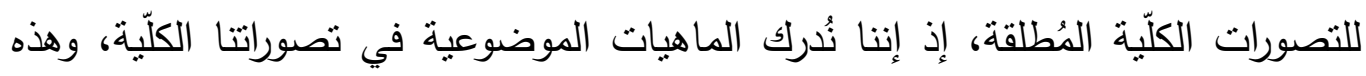

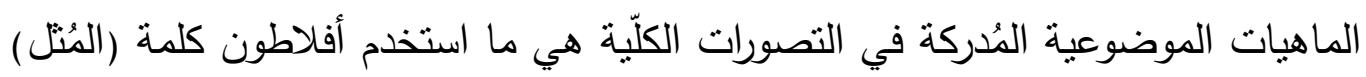

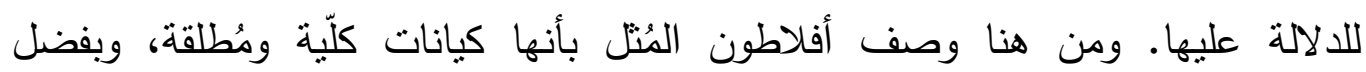

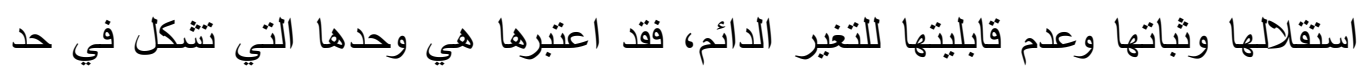

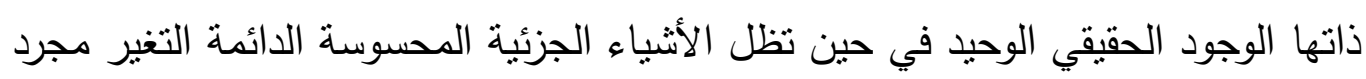

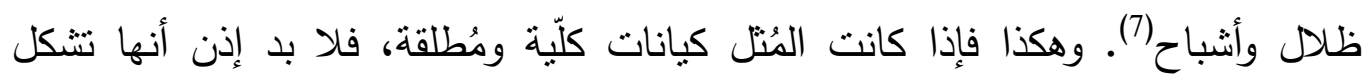

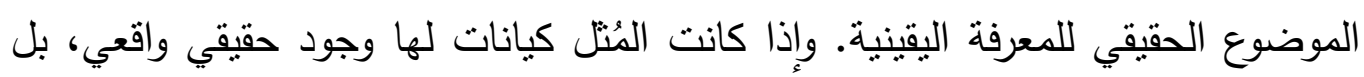

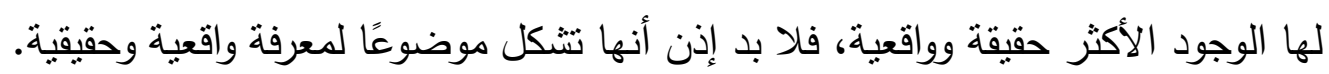

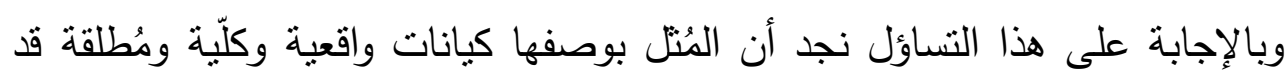
حققت بالفعل الثرطين الأساسيين للمعرفة اليقينية الوحيدة والممكنة في نظر أفلاطون. (ب) المثال المُطلق موضوعًا للمعرفة اليقينية: 


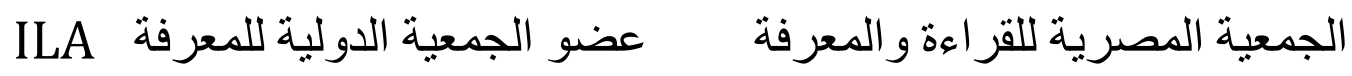

إنه على الرغم من الانتقادات التي وجهها أفلاطون لكلّ من المعرفة الحسّية والمعرفة

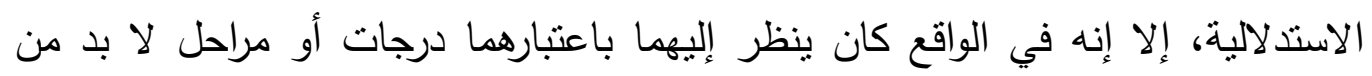

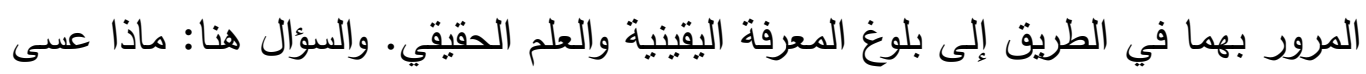

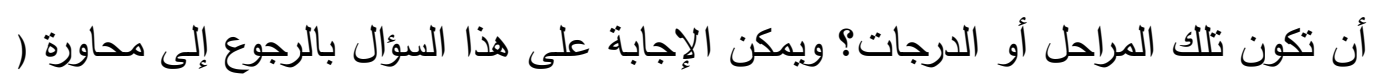

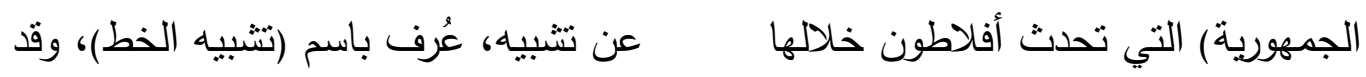

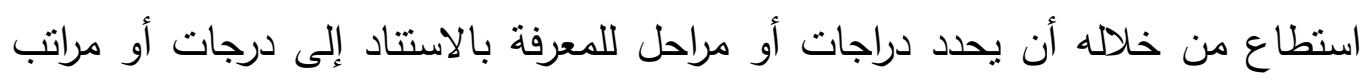

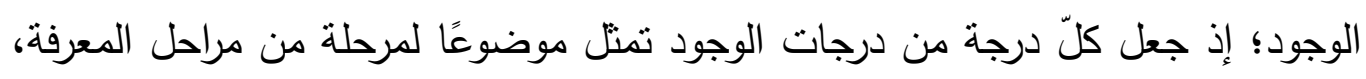

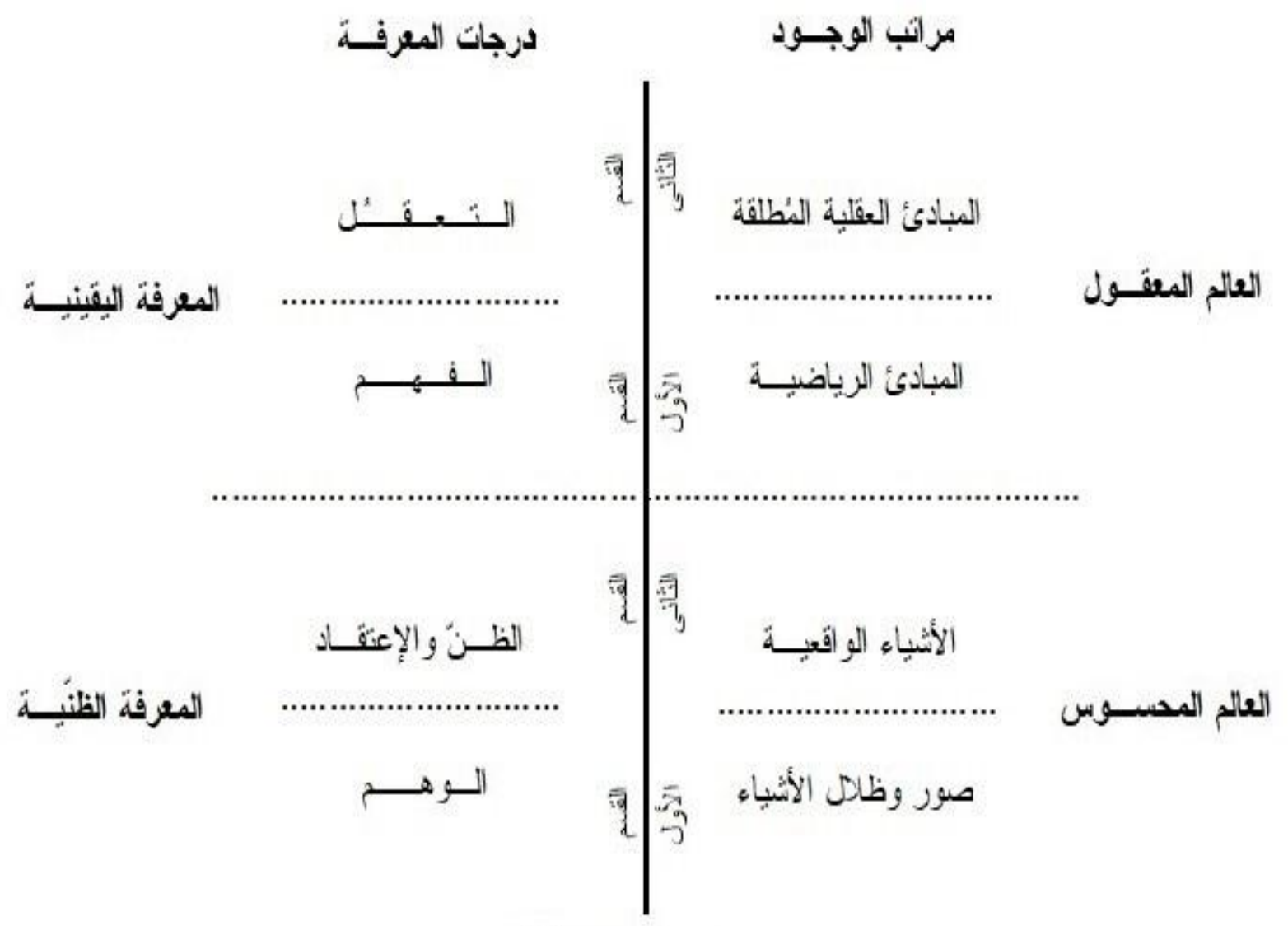

() نثبيه الخــا 


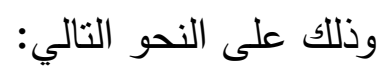

افترض أفلاطون، كما في الثنكل السابق، أنه يمكن تصور الوجود ككلّ على أنه

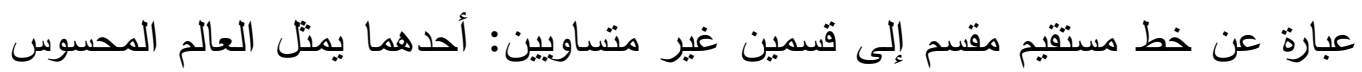
والآخر يمنل العالم المعقول. أما العالم المحسوس فهو في مجمله يمنل موضوعًا للمعرفة

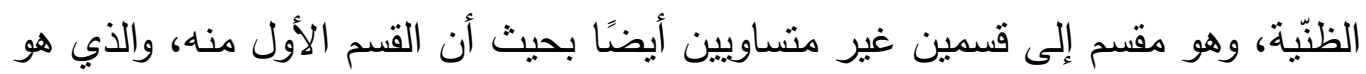

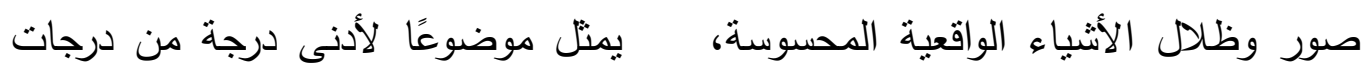

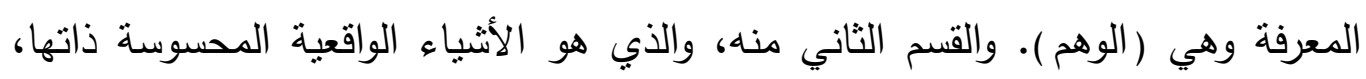

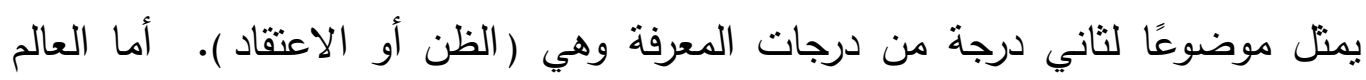

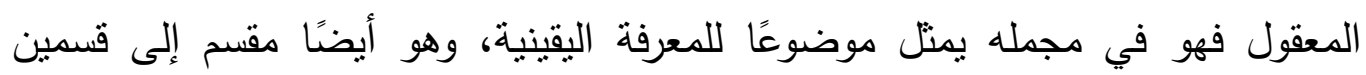

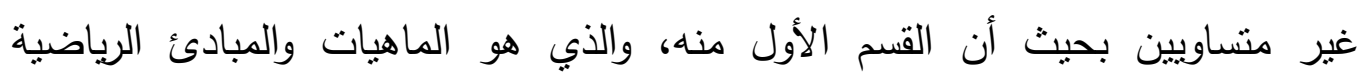

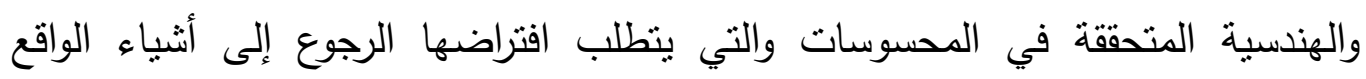

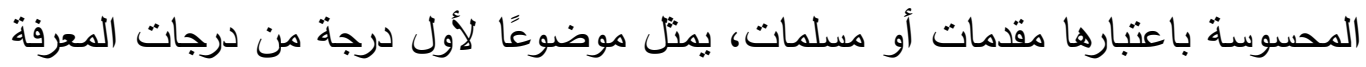

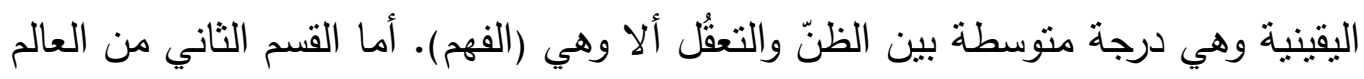

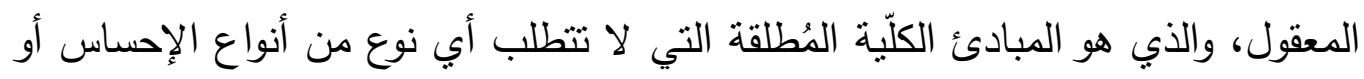

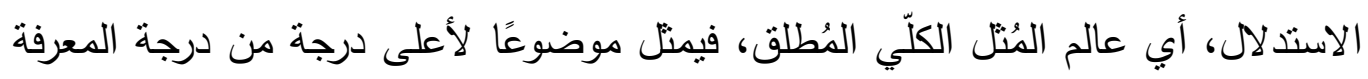

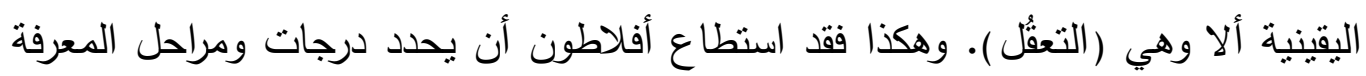

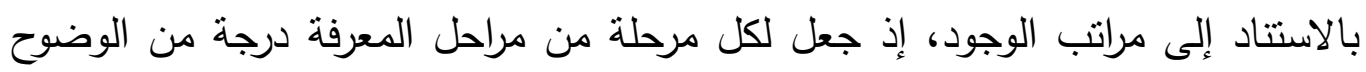

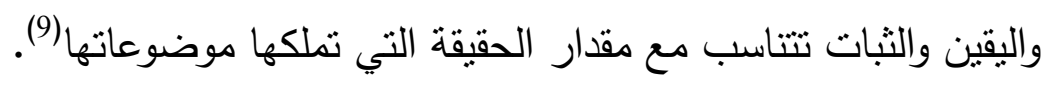

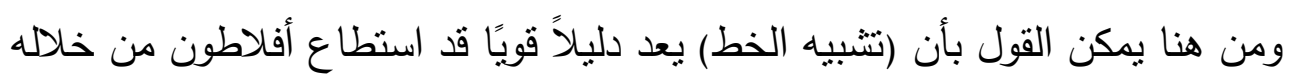

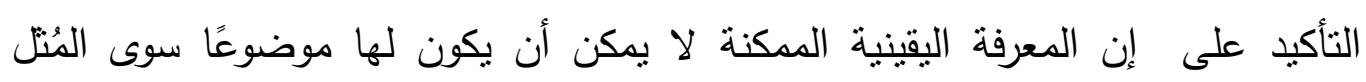

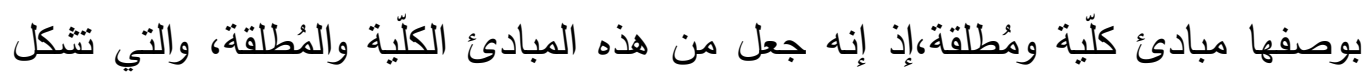

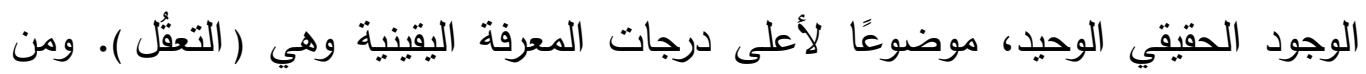


الممكن تدعيم هذه النتيجة من خلا الرجوع إلى تنتبيهين آخرين عرضهما أفلاطون أيضًا

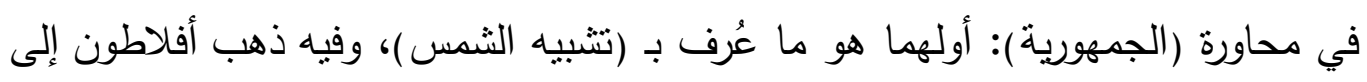

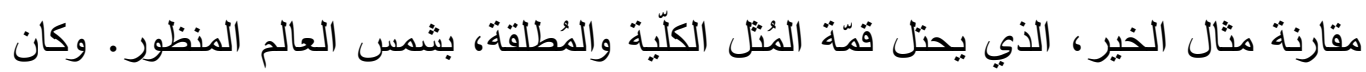
هدفه من هذه المقارنة التي أقامها بين مثال الخير والثنمس هو الثأكيد على أن منزلة مثال

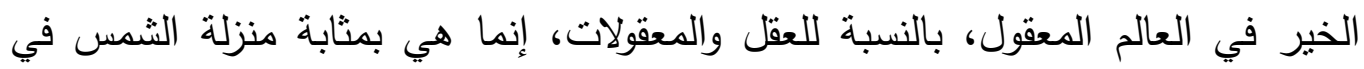

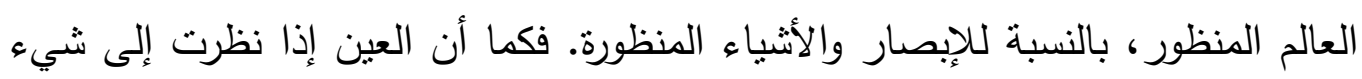

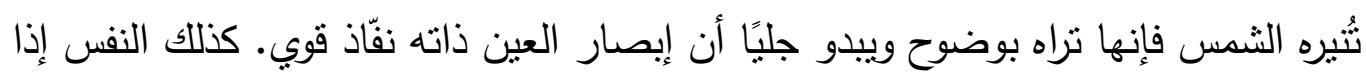

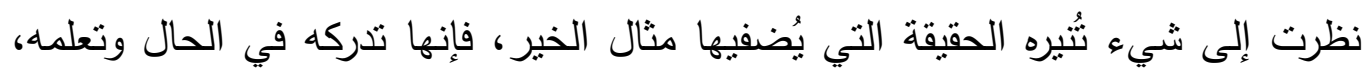

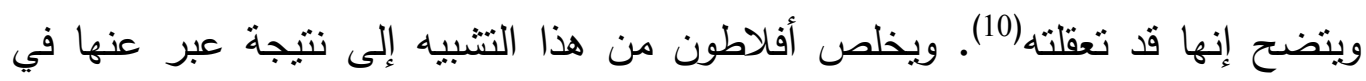

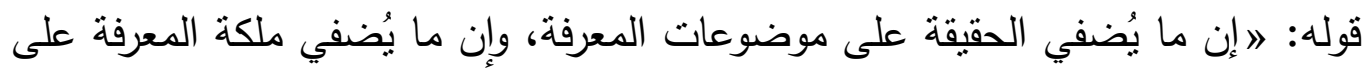

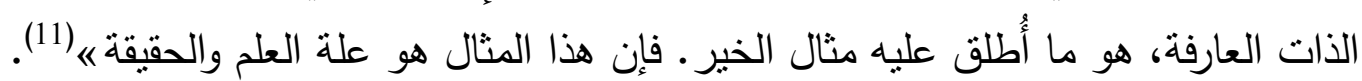

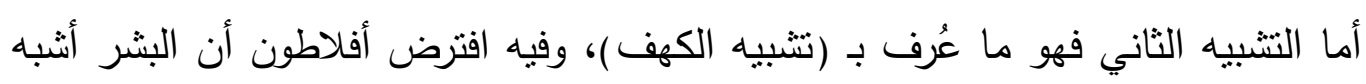

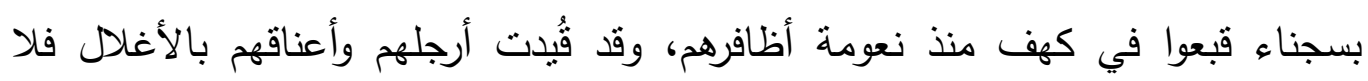

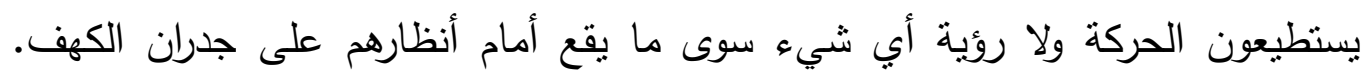

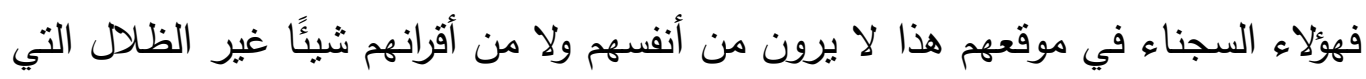

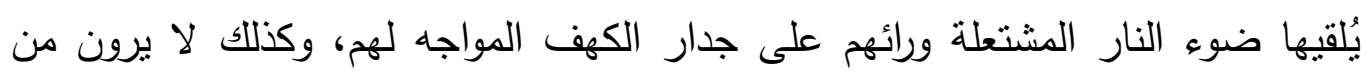

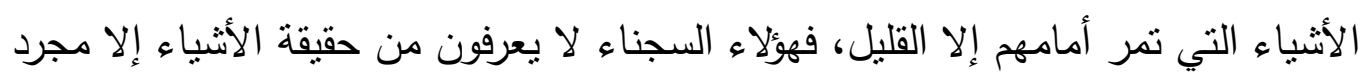

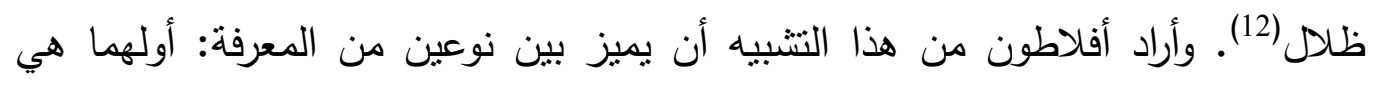

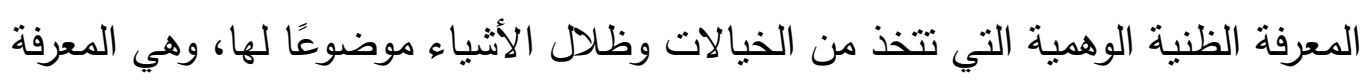

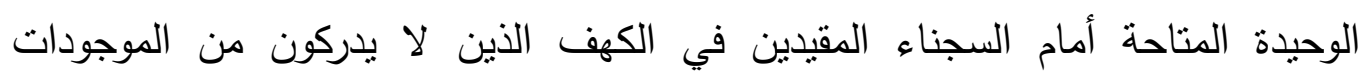

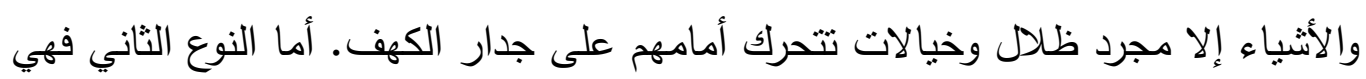

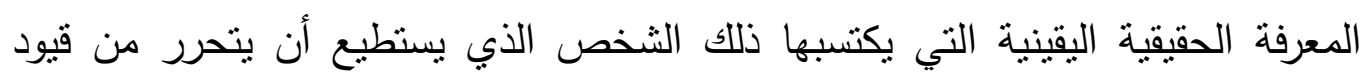


الكهف وينمكن من الصعود إلى خارج الكهف ليرى ويدرك ويتعقل الأثنياء على حقيقتها.

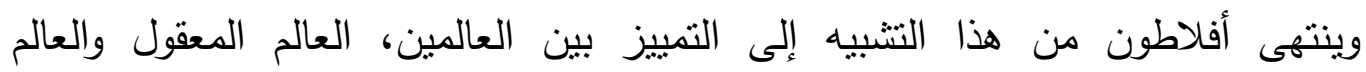

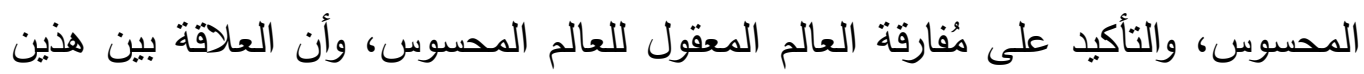

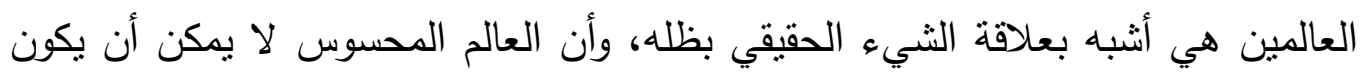

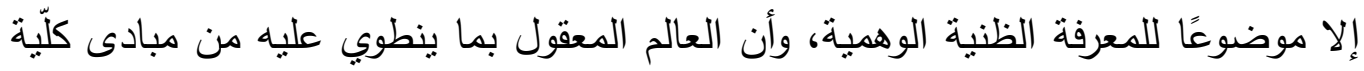

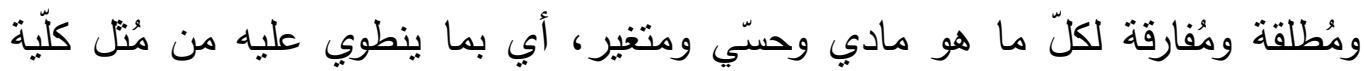
ومُطلقة، هو وحده الذي يمكن أن يكون موضوعًا للمعرفة الحقيقية اليقينية. وبإمعان النظر في التنبيهات الثنلاثة السابقة، الخط والثنمس والكهف، يمكن استتناج أنها تتكل معًا حلقة متكاملة. إذ إن كل هذه التشبيهات في الواقع لا تهدف إلا إلى محاولة

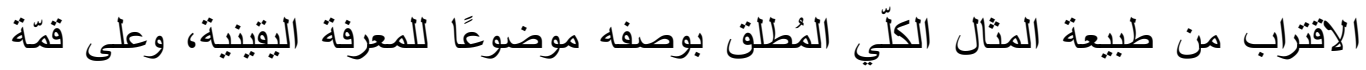

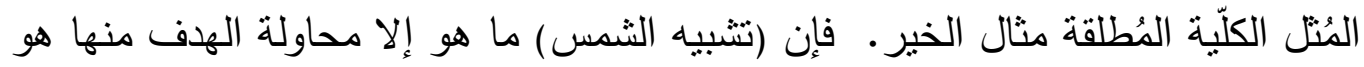

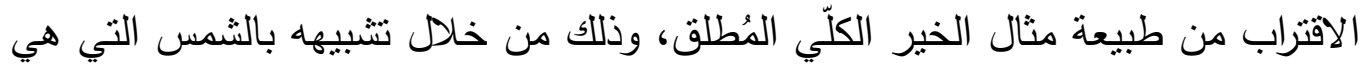

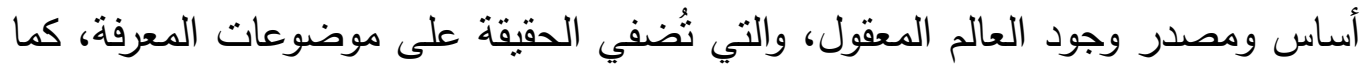

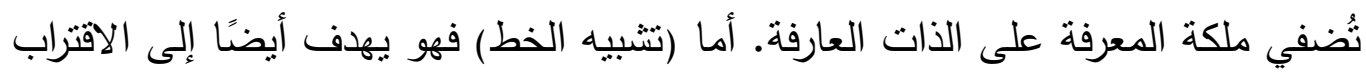

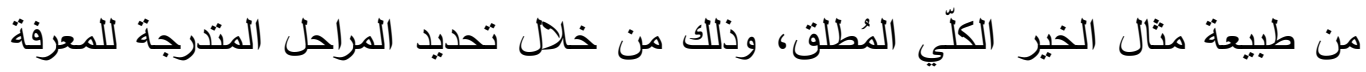

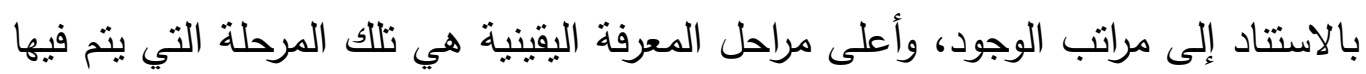

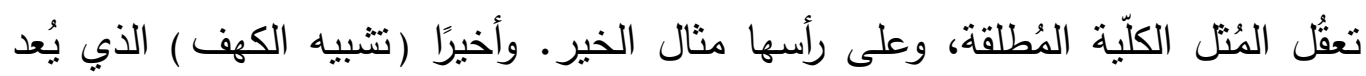

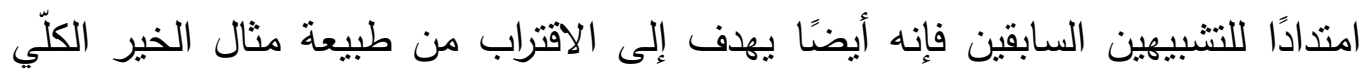

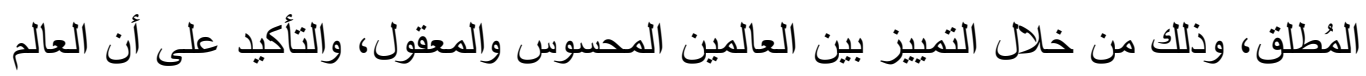

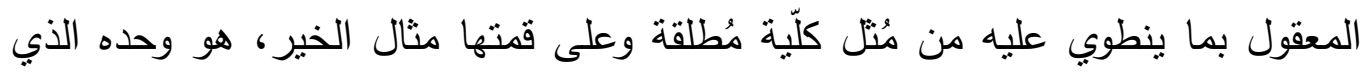

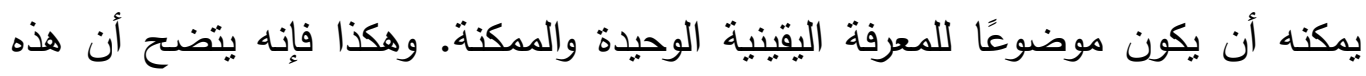
التشبيهات الثثلاثة تتشرك في هدف واحد وأساسي هو محاولة الاقتراب من طبيعة المثال 
الكلّي المُطلق الذي هو مصدر كلّ معرفة حقيقية وكلّ وجود حقيقي. وعلى الرغم من أن

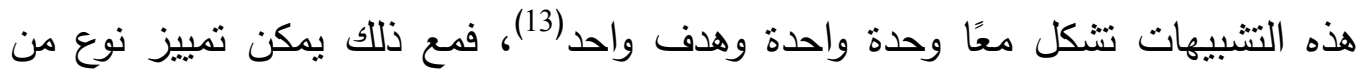
التخصص في كلّ تشبيه على حدى. فبالنظر إلى ( تثبيه الثشمس ) نجد أنه يتعلق

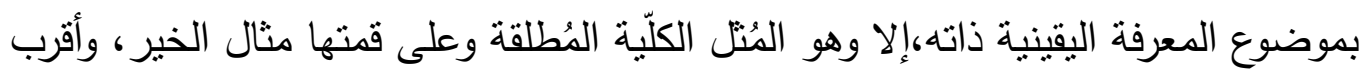

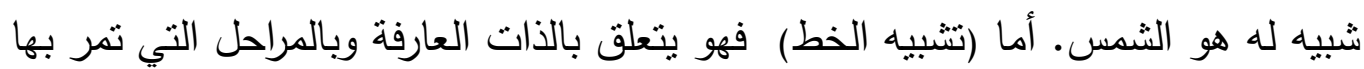
بداية من الظلاد والأوهام ووصولاً إلى المعرفة اليقينية ذاتها وموضوعها هو المُتل الكلّية اليُطلقة. أما (تثبيه الكهف) فيتعلق بكلّ من الذات العارفة وموضوع المعرفة معًا؛ إذ إنه يتعلق بالمراحل التي تمر بها الذات العارفة بداية من وجودها مقيدة في الكهف ومحاصرة بالأوهام والظلال ووصولاً إلى تحررها من قيود وأوهام هذا الكهف وروئية الأثياء

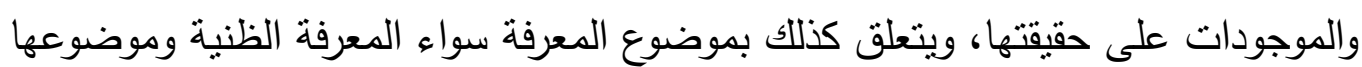

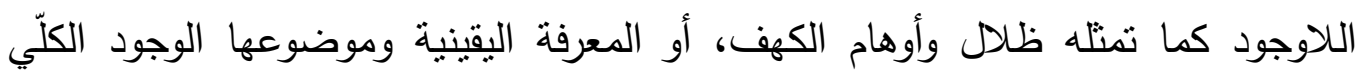
الكامل اليُفارق لكلّ ما هو مادي وحسّي ومتغير إلا وهو عالم اليُّلت الكلّي اليُطلق (14).

\section{(ج) طبيعة المعرفة اليقينية:}

بناءًا على ما سبق يمكن الانتهاء إلى نتيجة مفادُها أن كلّ علم حقيقي، عند

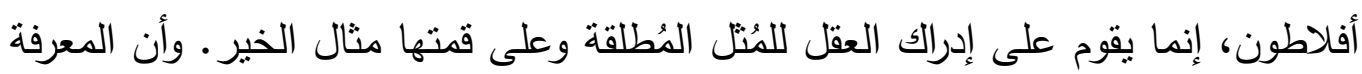

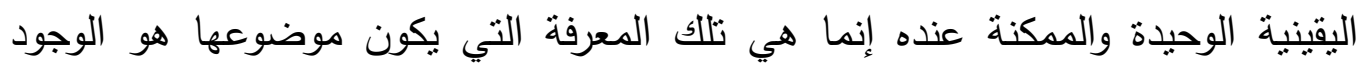

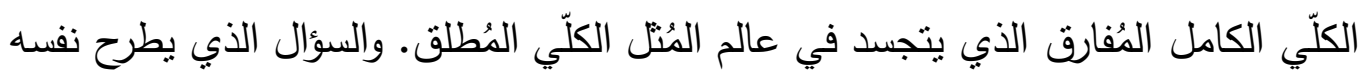

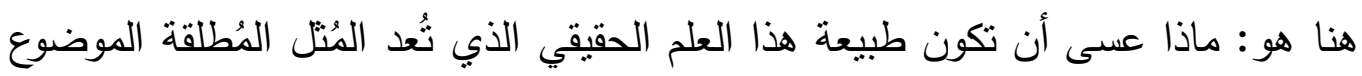

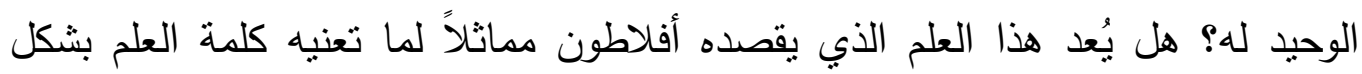

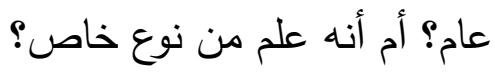
والواقع إن تحديد طبيعة العلم الذي يقصده أفلاطون يستلزم بضرورة تحديد طبيعة

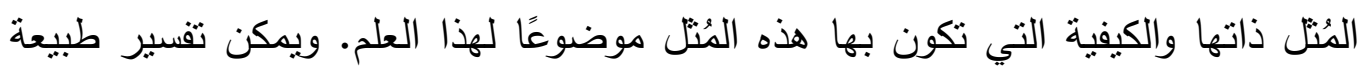


الكُّنل الكلّية المُطلقة على أنها تُعبر عن الثُرط الأساسي الذي ينبغي أن يتصف به كلّ

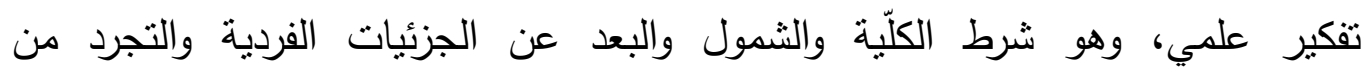

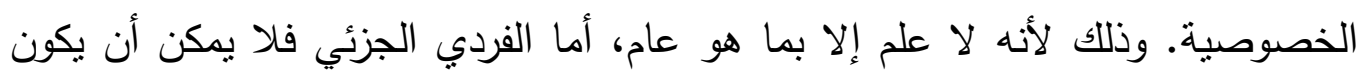

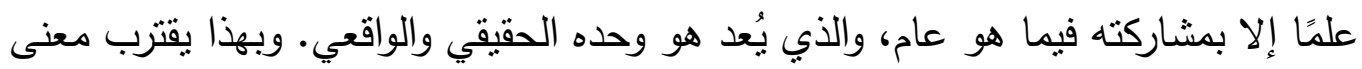

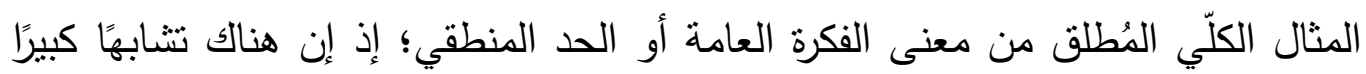

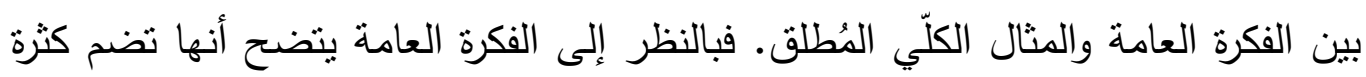

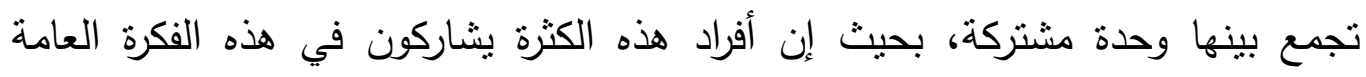

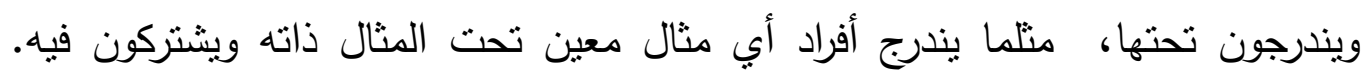

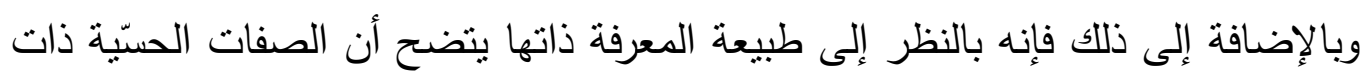

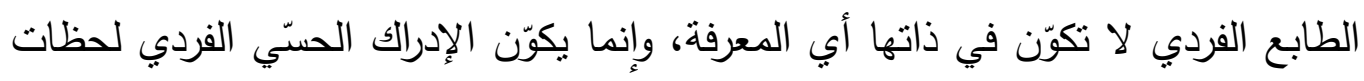

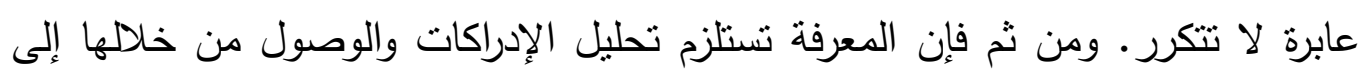

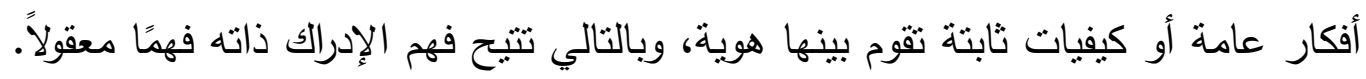

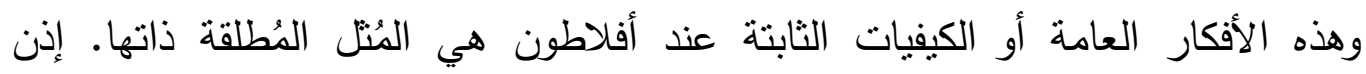
فالمعرفة لا تكون ممكنة وسط كثرة المتغيرات إلا بوجود نقاط الارتكاز الثابتة وهي الأفكار

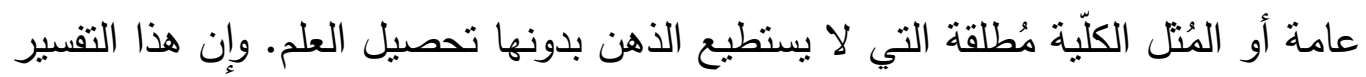

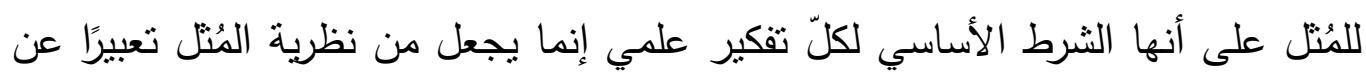

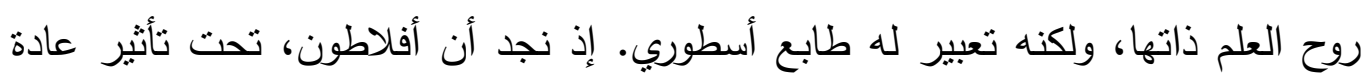

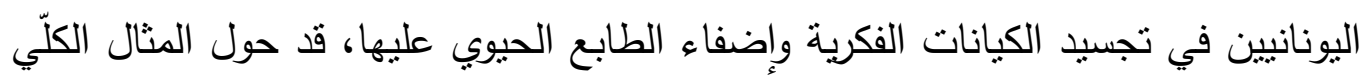

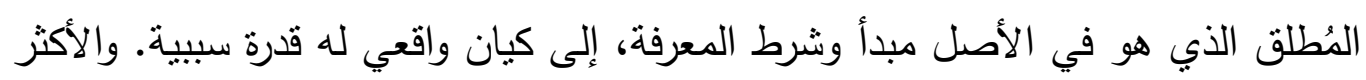

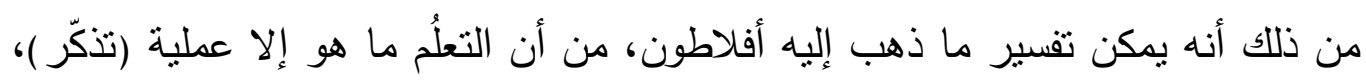

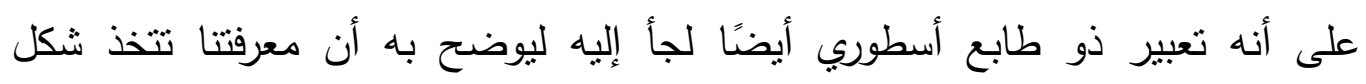

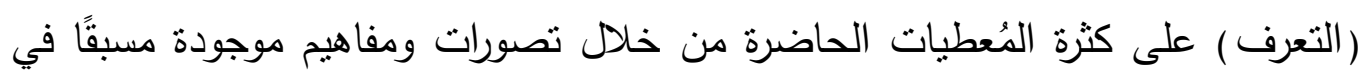


الذهن. ومن ثم فإن عملية التعرف هذه ليست إلا نوعًا من التذكّر يتم من خلالها إدراك الكثرة المتغيرة التي نمر بها في اللحظة الراهنة بالرجوع إلى عناصر ثابتة لها في الذهان الذهن

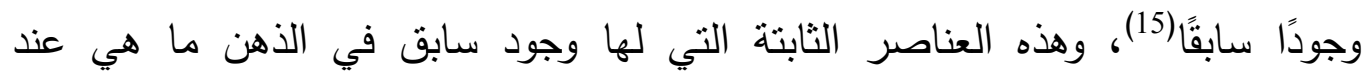
أفلاطون إلا مُنتل كلَّة مُطلقة.

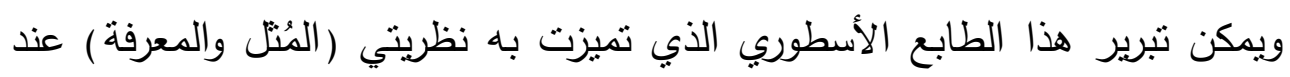

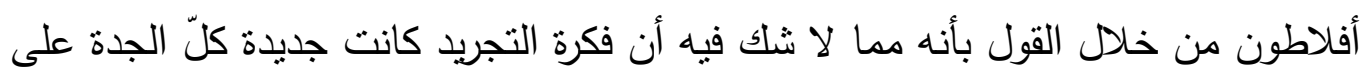

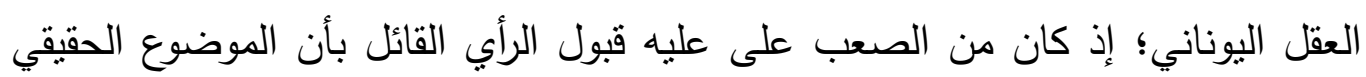

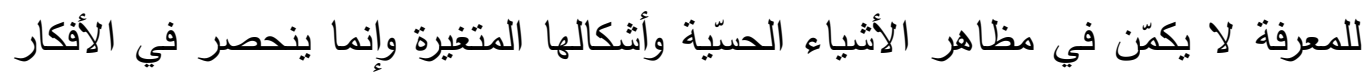

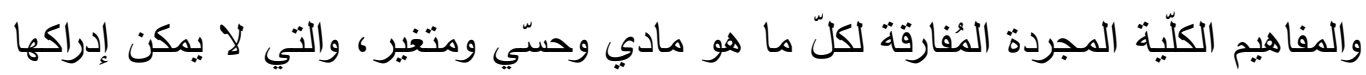

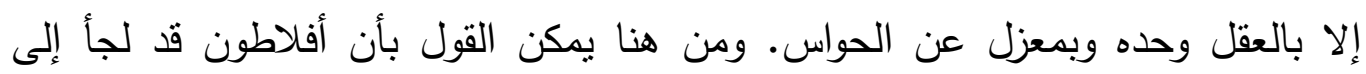

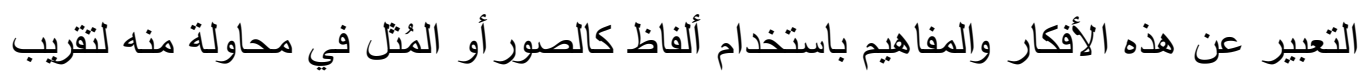

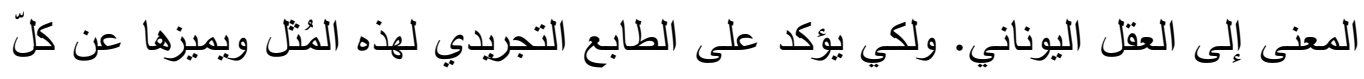

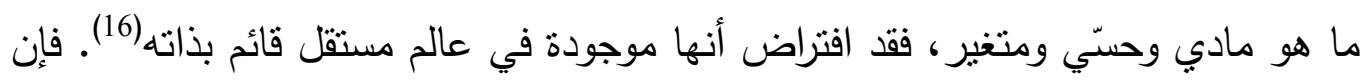

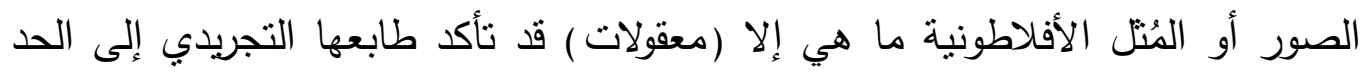

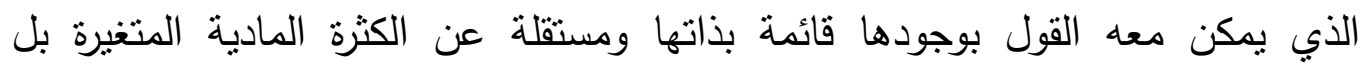

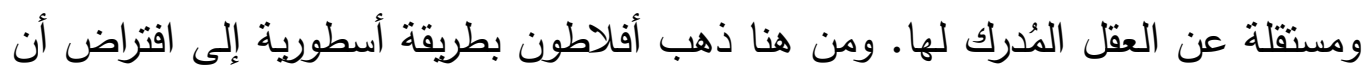

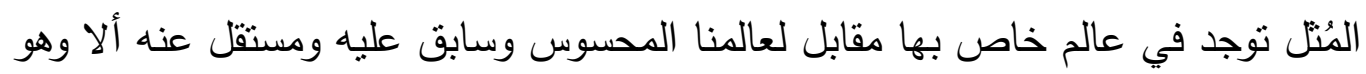

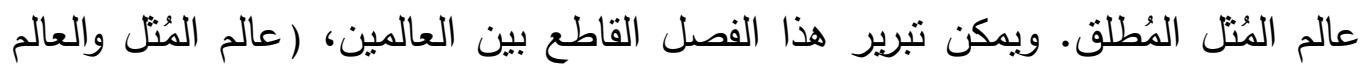

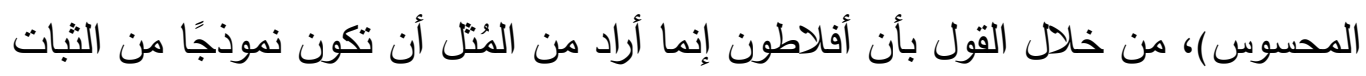

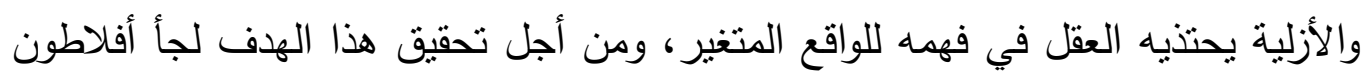

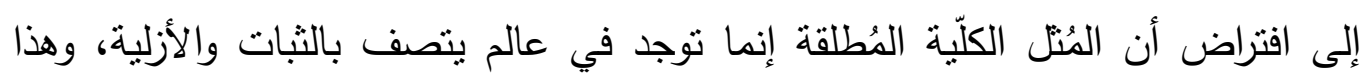

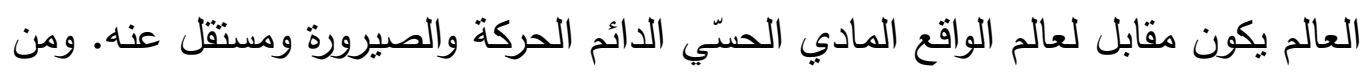


جهة أخرى أراد أفلاطون أن يسلب من الأثنياء والظواهر المادية الحسيّة صفة الوجود

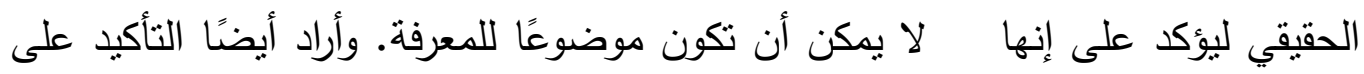

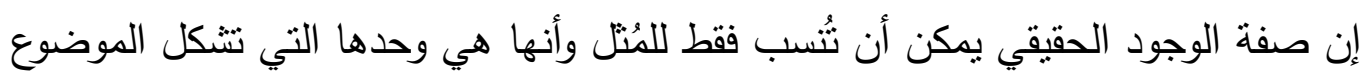

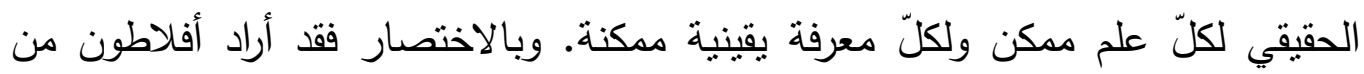

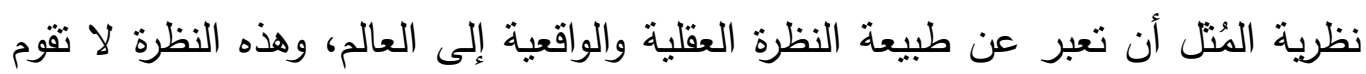

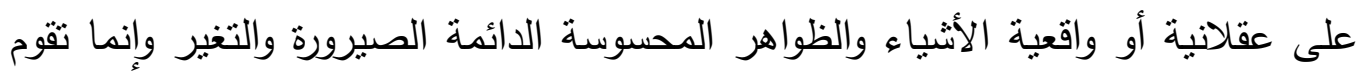

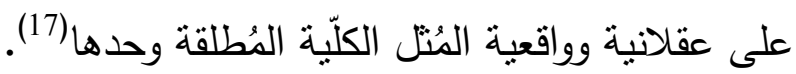
ثانيًا: المنهـج الجدلي ويلوغ المعرفة البقينية: ويتضح مما سبق أن العلم الحقيقي الذي قصده أفلاطون هو العلم بالمبادئ الكلّية

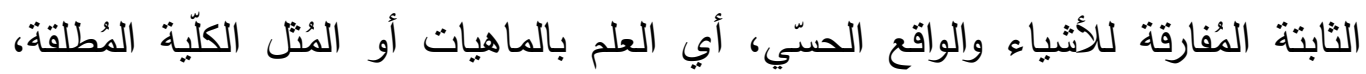

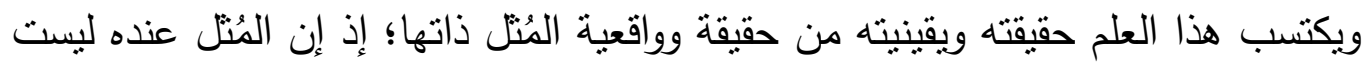

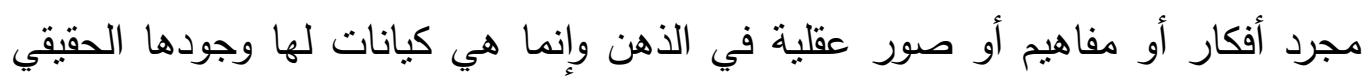

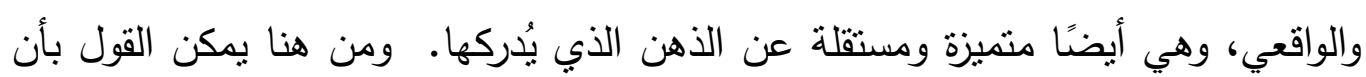

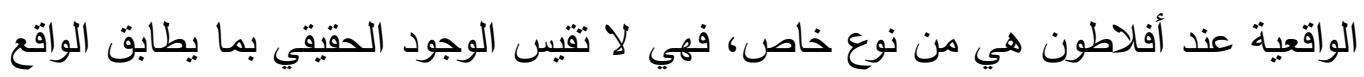

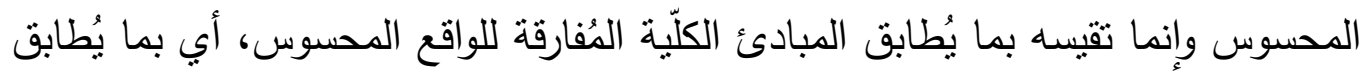

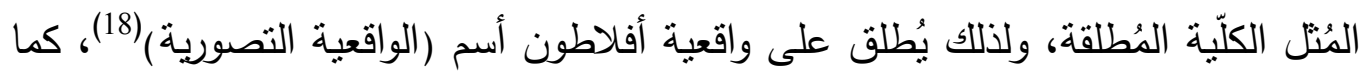

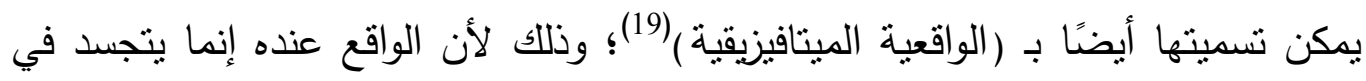

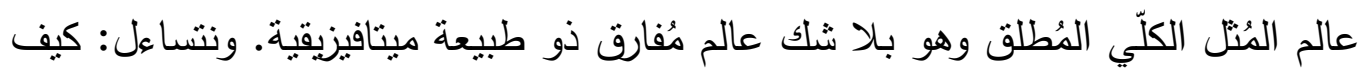

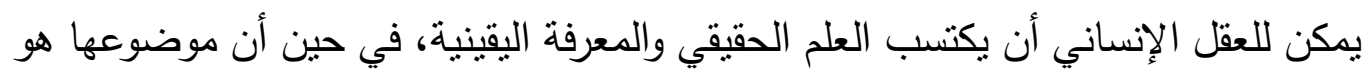

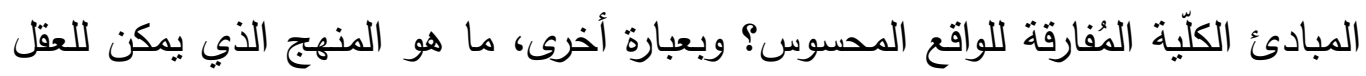

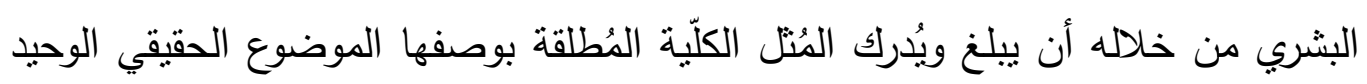

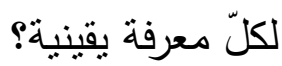


إن بلوغ وإدراك المُتنل الكلّية المُطلقة ومن ثم اكتساب العلم الحقيقي والمعرفة اليقينية

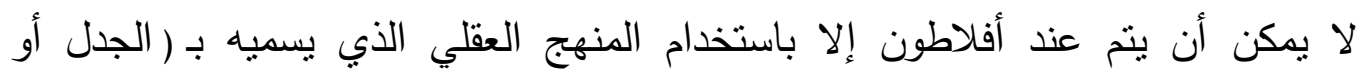

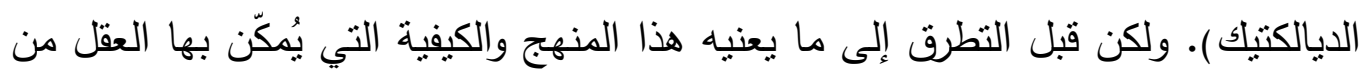

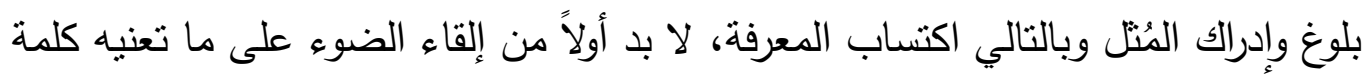

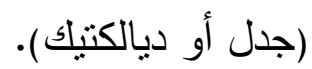

( أ ) الجدل في معناه اللغوي والاصطلاحي:

Dialektike فialectic الجي اللغة الإنجليزية مشتق من الفعل اليوناني"

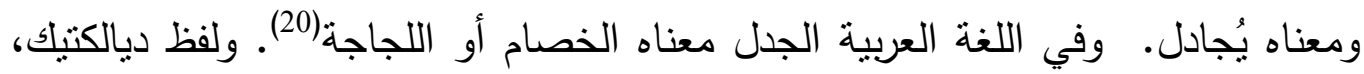
في الأصل اليوناني، مكون من مقطعين: Dia ويعنى التبادل، و وDialecktos ويعنى

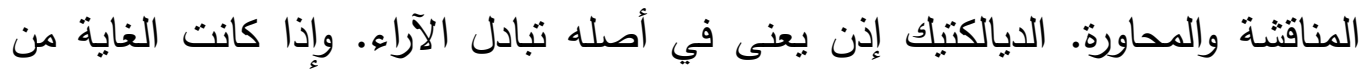

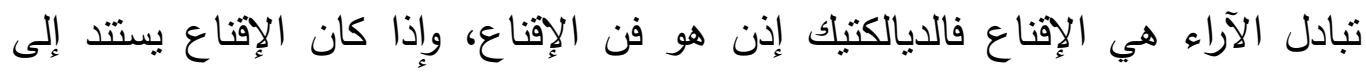

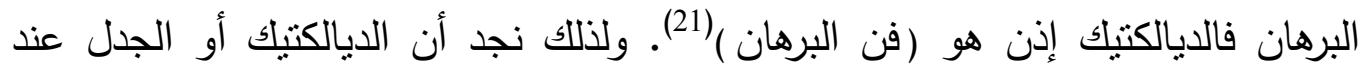

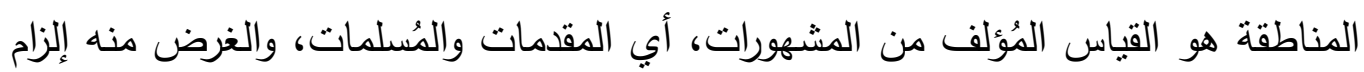

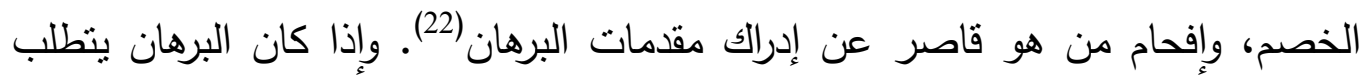

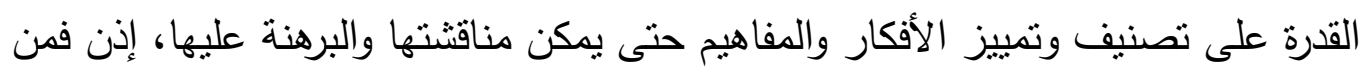

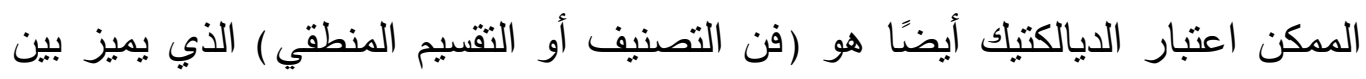
الأنواع والأجناس (23). (ب ) الجدل في الفلسفة السابقة على أفلاطون: بالنظر إلى المسار التاريخي لظهور فن الجدل والبرهان نجد أنه بالرغم من أن كلمة النها

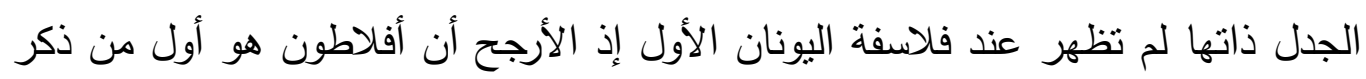

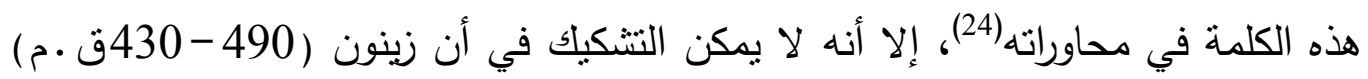

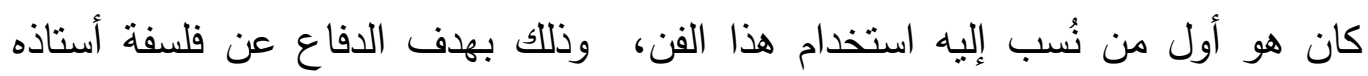


بارمنيدس (530-440ق م)، ويمكن التدليل على ذلك بالرجوع إلى قول أفلاطون نفسه

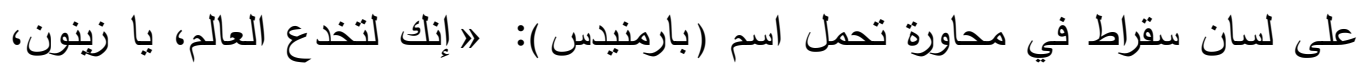

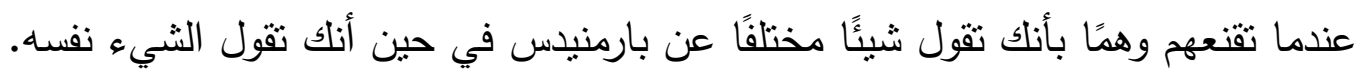

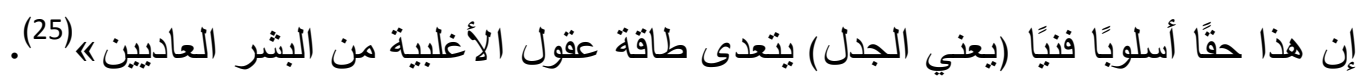

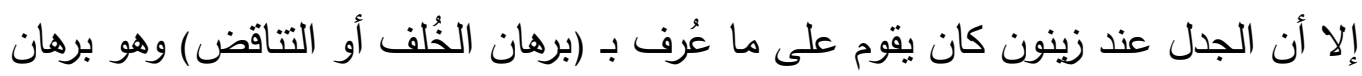

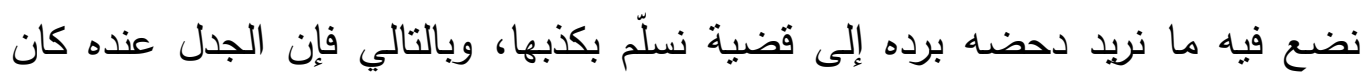
يهدف إلى الكثف عن المتتاقضات غير المشروعة بناءًا على قياس باطل، وهذا القياس الباطل هو في حقيقته سفطة؛ وذلك لأن الثخص الذي يقوم بهذا النوع من القياس يكون على علم بطلانها، ولكنه يريد مغالطة خصمه والتمويه عليه. ومن هذه الجهة، ومنها وحدها، يمكن القول بأن الديالكتيك عند زينون كان هو الممهذ لظهور الجدل في شكله السوفسطائي، وهو جدل يعتمد في المقام الأول على إمكانية تأييد القول الواحد ونقيضه

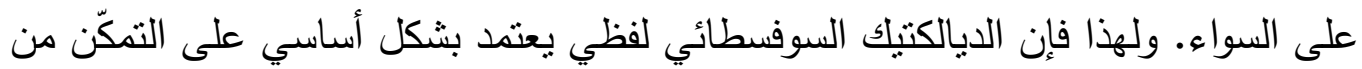
اللغة، والعلم والمعرفة بأسرار الألفاظ، وتركيب العبارة، وحسن البيان. وبالنظر إلى هذه

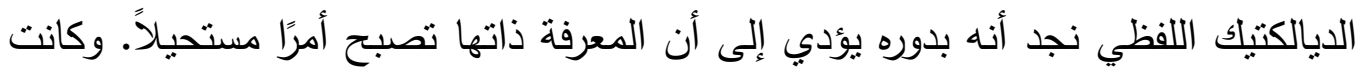
هذه هي النتيجة التي انتهى إليها الفيلسوف السوفسطائي غورغياس (483-375ق .م) وقد عبر عنها في قضايا ثلاثة: الأولى تتص على أنه لا يوجد شيء، والثانية تنص على أنها

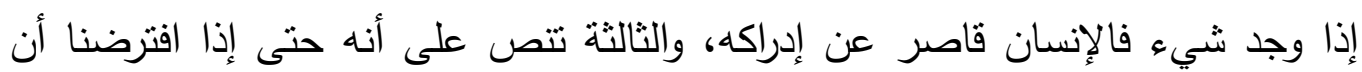

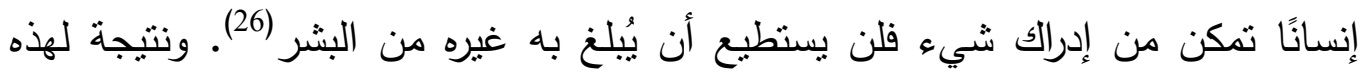

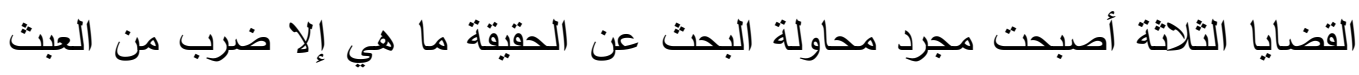

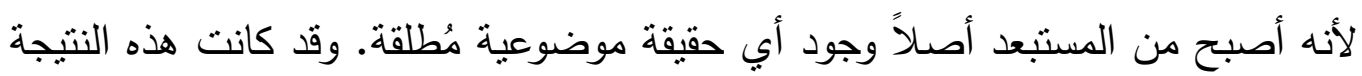

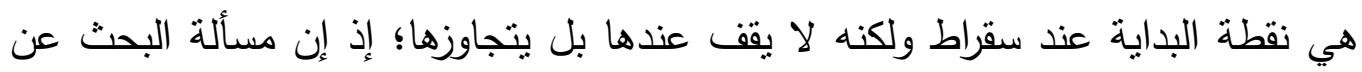

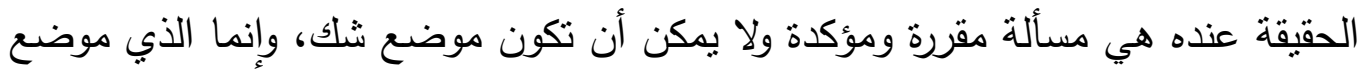


الثثك هو (نتيجة البحث) وليس البحث ذاته. وهذا معنى القول بأن حكمة سقراط كانت

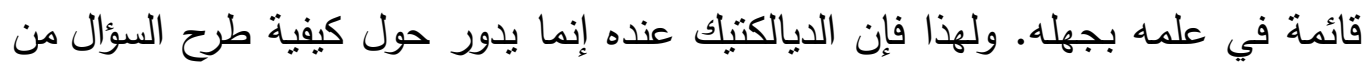

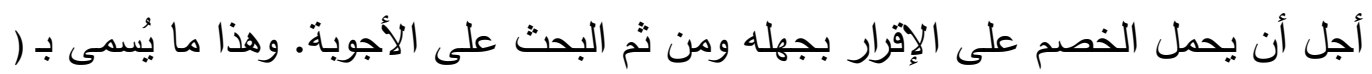

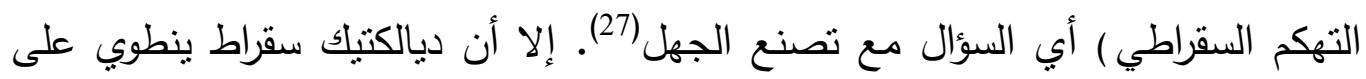

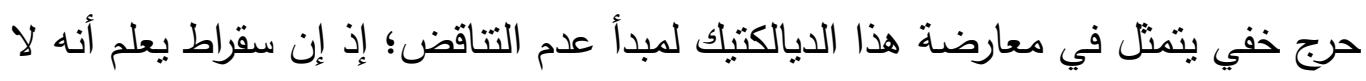

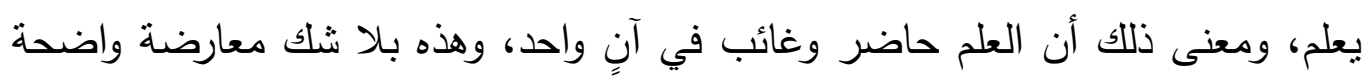

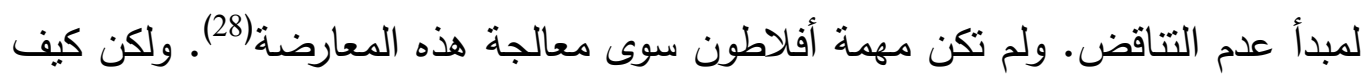

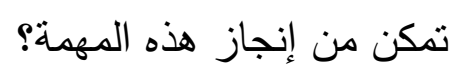

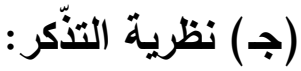

الواقع إن نظرية أفلاطون عن (التذكّر ) كانت هي الوسيلة الأساسية التي تنكن بها

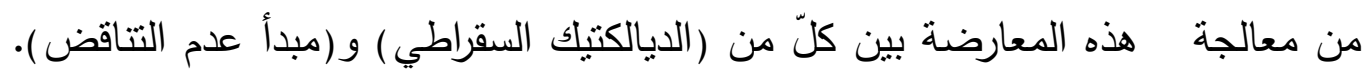
وقد عرض أفلاطون هذه النظرية في محاورة (فيدون) أنثاء حديثه عن أدلة خلود النفس،

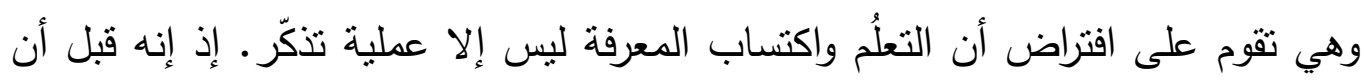

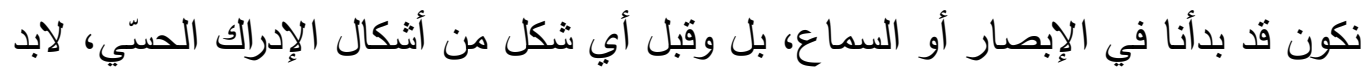

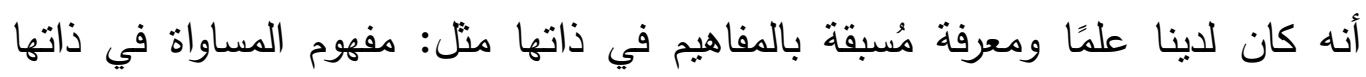

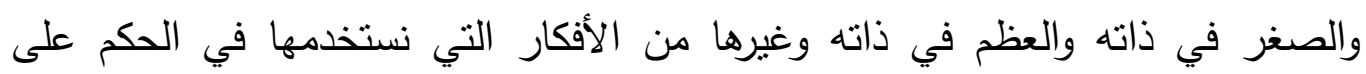

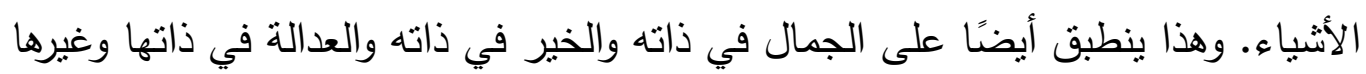

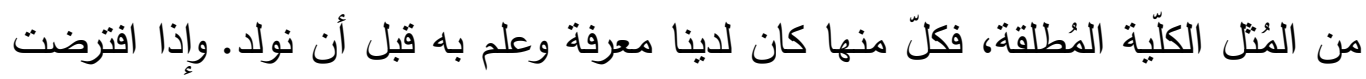
أننا قد فقدنا، أثناء مبلادنا، ما كنا حاصلين عليه من علم ومعرفة قبل الميلاد، وإذا تمكنا بعد ذللك من استعادة العلوم التي كنا حاصلين عليها بالفعل من قبل باستخدام الحواس،

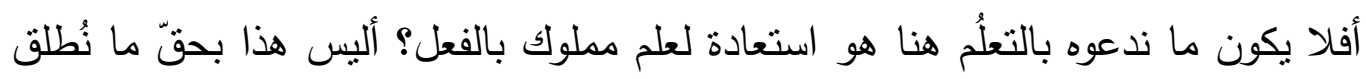


عليه (التذكّر )؟ وهكذا إذن فلابد أن نفوسنا كانت موجودة وجودًا سابقا، قبل أن تتخذ الثكل الإنساني، منفصلة عن الجسد، وحائزة على العلم (29). وهنا نتساءل: أين كانت النفس إذن قبل اتصالها بالبدن وقبل أن تتخذ الثكل

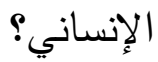

يجيب أفلاطون على هذا السؤال في محاورة (فايدروس) التي ذهب فيها إلى القول

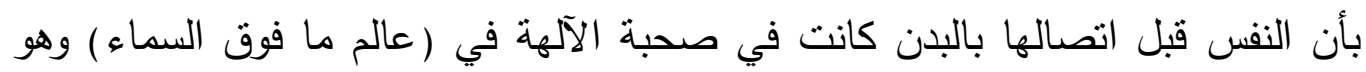

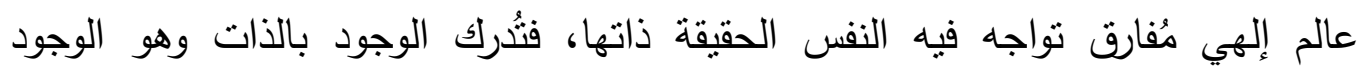

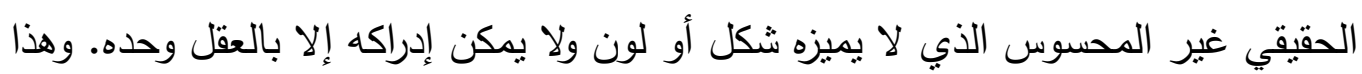

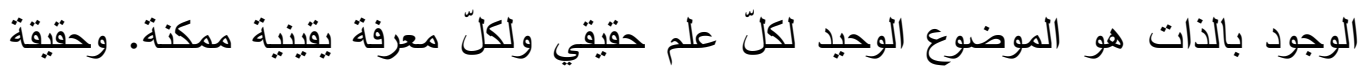

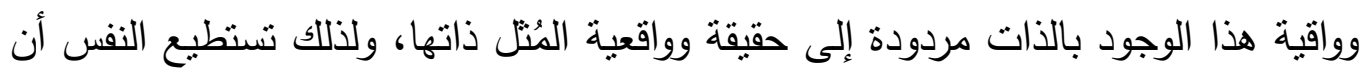
تتأمل وثُرك، في هذا العالم الإلهي الدُفارق، العلم المُطلق، والحكمة والمعرفة التي لا بطرأ

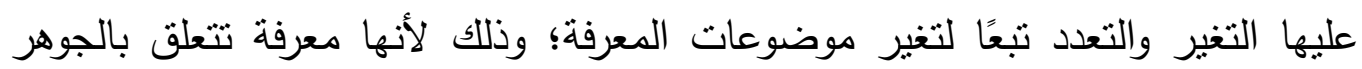
الحقيقي الثابت للوجود. ويحدث الثفاوت بين البشر عندما تتخذ النفس الثنكل الإنساني

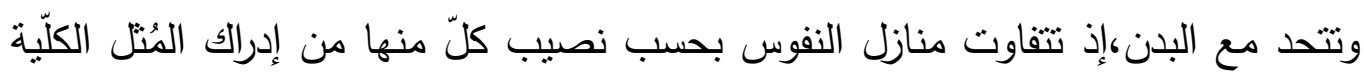

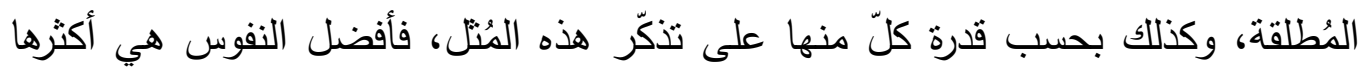
قدرة على إدراك الكُّل المُطلقة وتذكّرها (30). ومن الجدير بالتتويه هنا أن نظرية (التذكّر ) تثثير في الواقع إنكالية غاية في الأهمية،

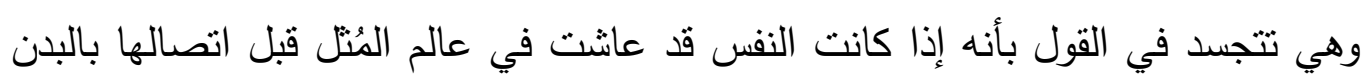

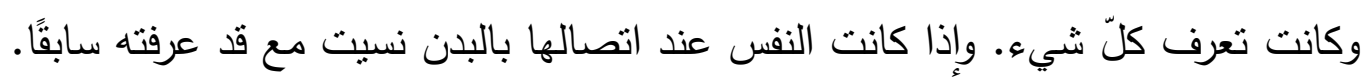

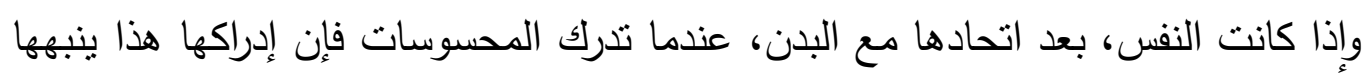


إلى تذكّر ما كانت تعرفه من قبل في عالم المُتنل، ومن خلال هذا التنكّر يتشكل العلم

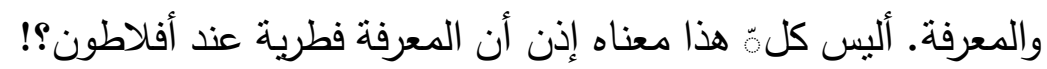

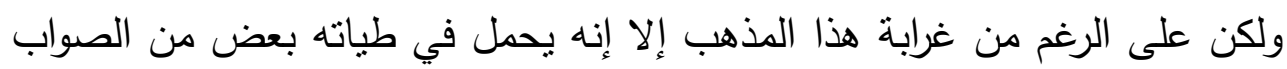

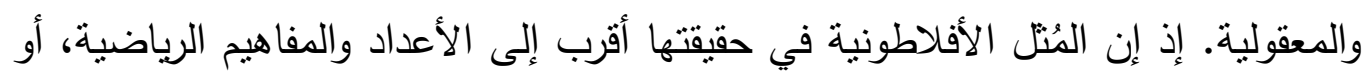

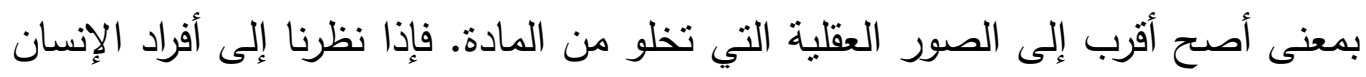

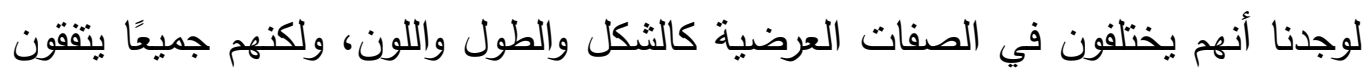
في شيء واحد هو مثال أو فكرة (الإنسان ) الخالية من أي مادة. ويرى أفلاطون أننا

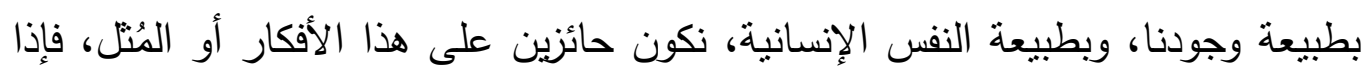

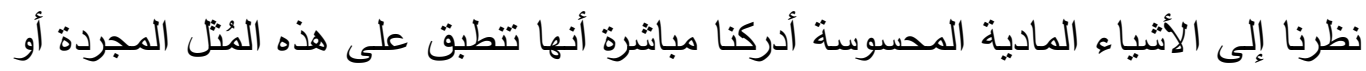

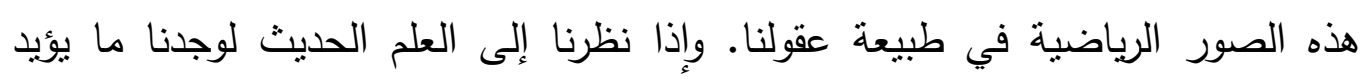

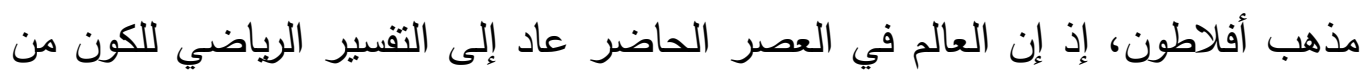

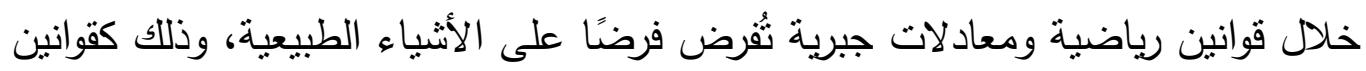

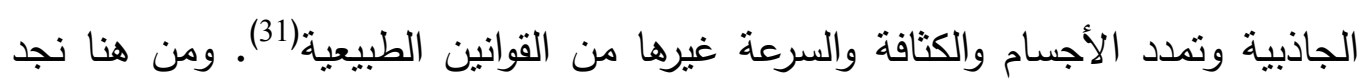

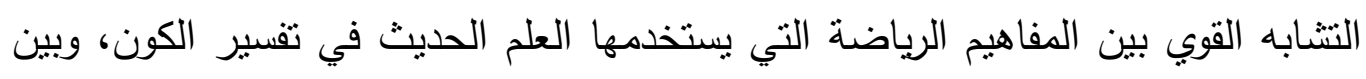

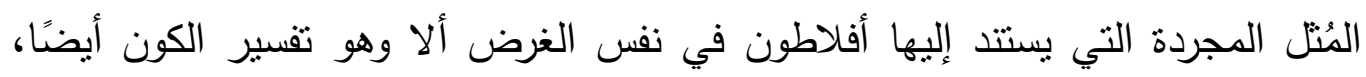

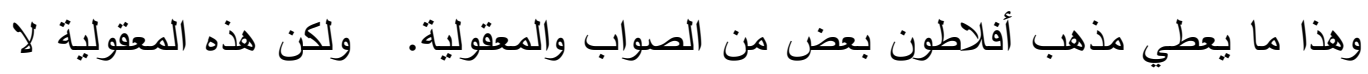

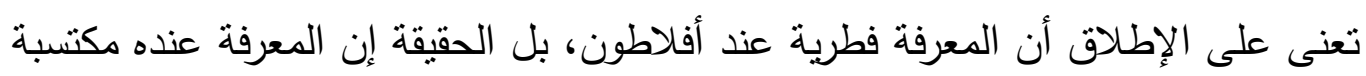

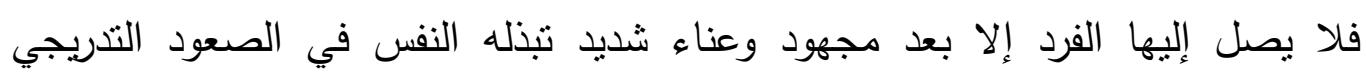

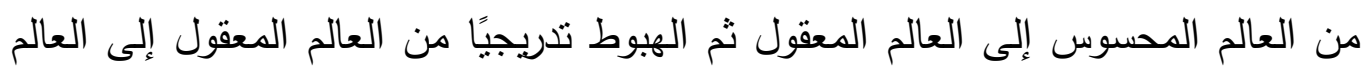

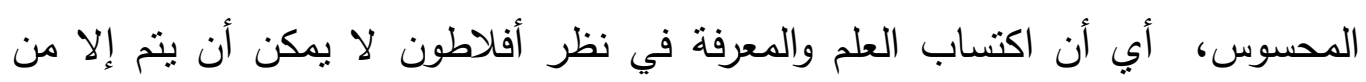

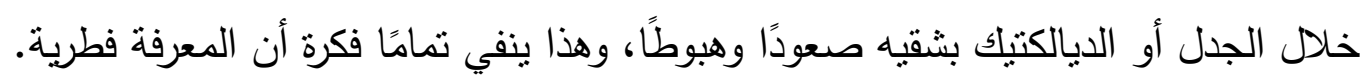




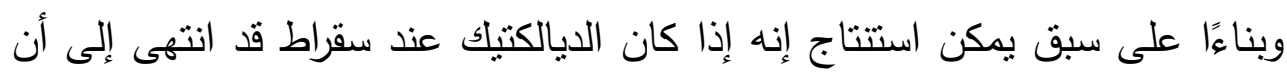

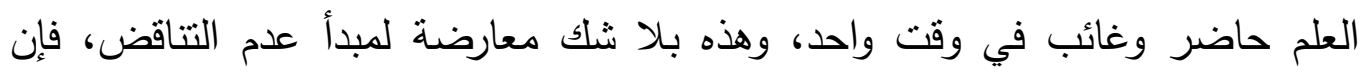

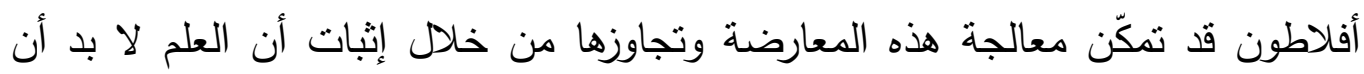

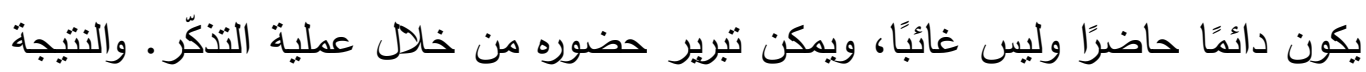

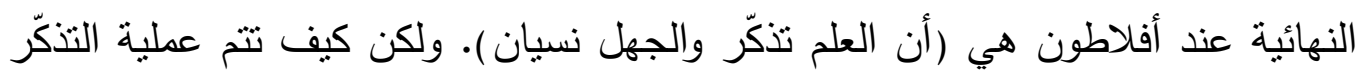

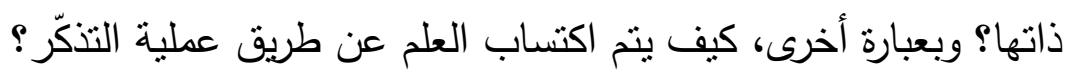

إن البحث عن جواب لهذا السؤال يؤدي مباشرًا إلى الجدل أو الديالكتيك الأفلاطوني؛

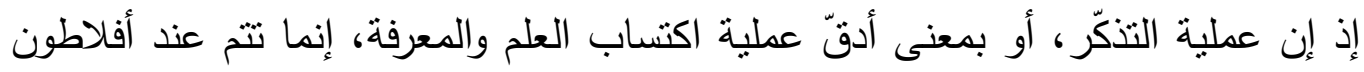

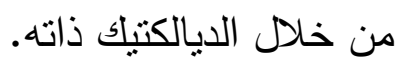

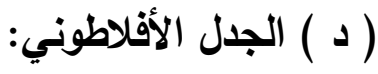

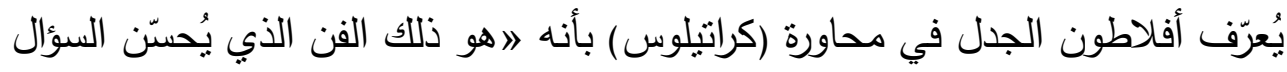

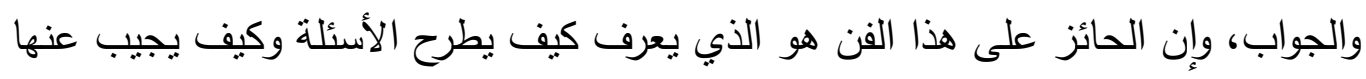

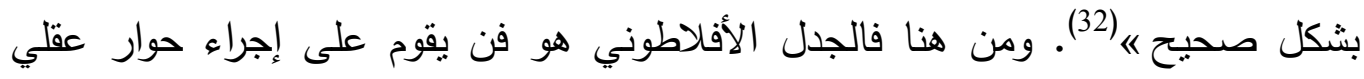

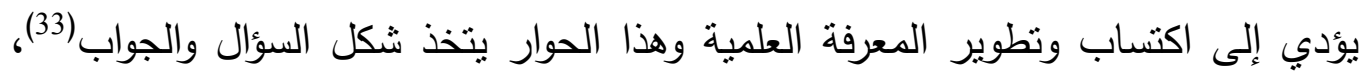

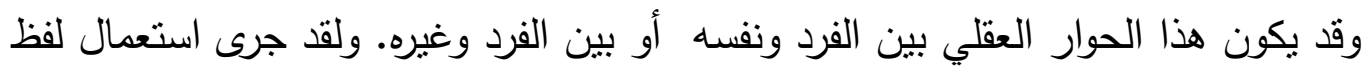

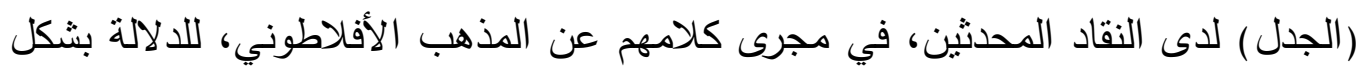

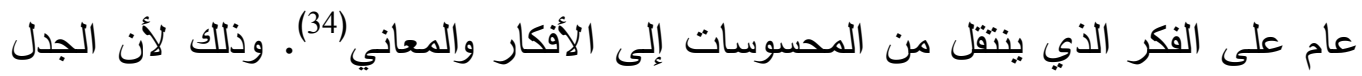

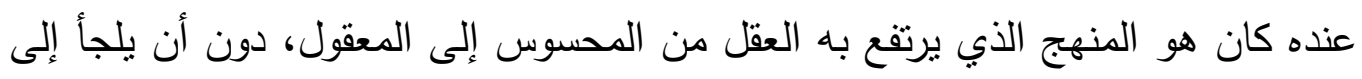

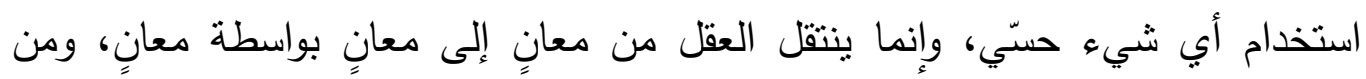

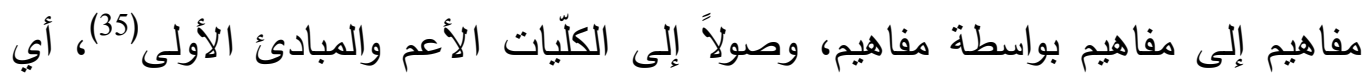

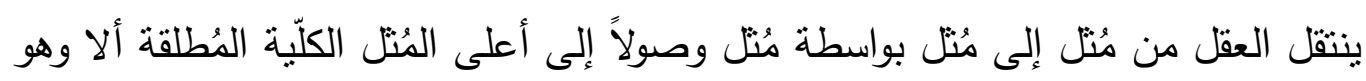

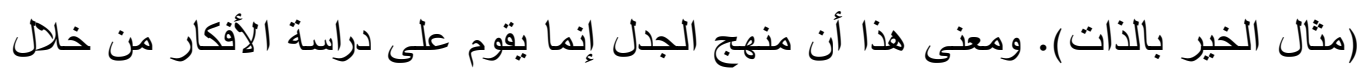


رد كلّ فكرة إلى فكرة أخرى أعم وأثنمل منها، ثم رد هذه الفكرة أيضًا إلى فكرة أخرى أعم وأثشمل من الفكرتين السابقتين، وهكذا حتى نصل إلى الفكرة التي هي أعم وأنشمل الأفكار

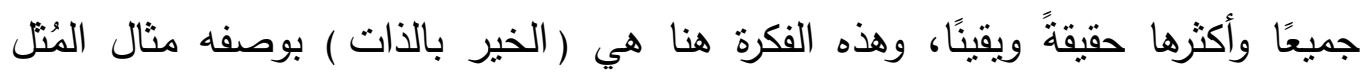

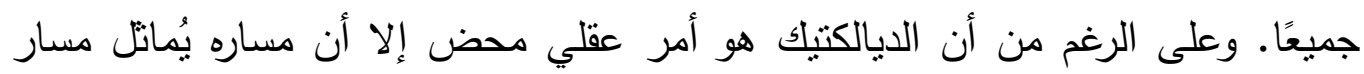

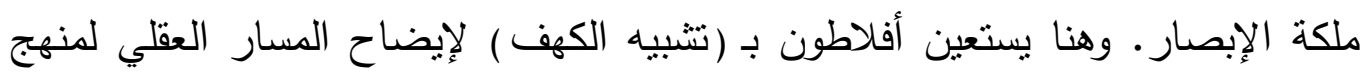

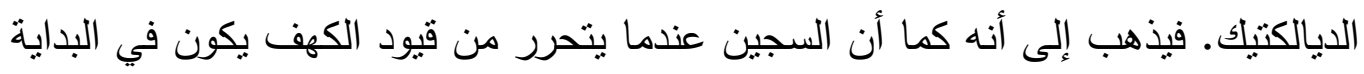

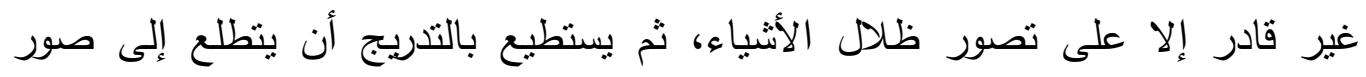

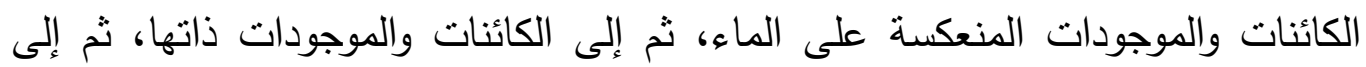

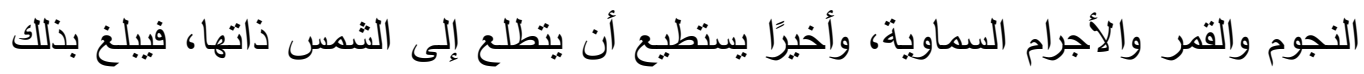

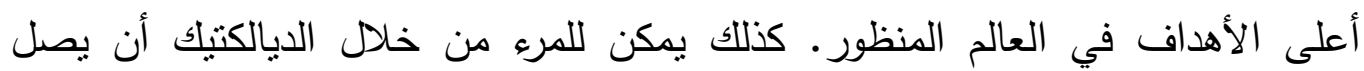

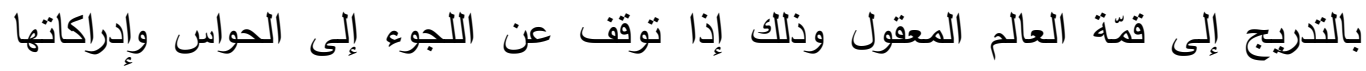

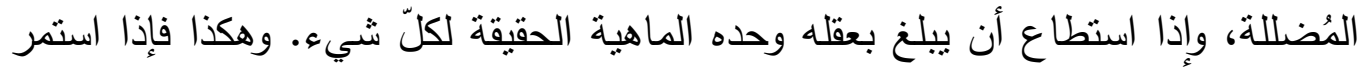

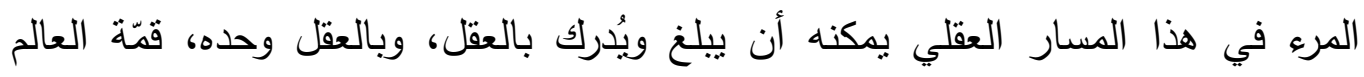
المعقول، إلا وهو مثال الخير ذاته. وهذا ما يمكن أن يُّمى (بالمسار الديالكتيكي بحقّ) (36).

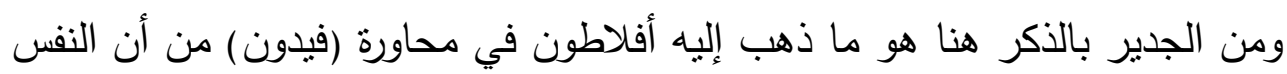

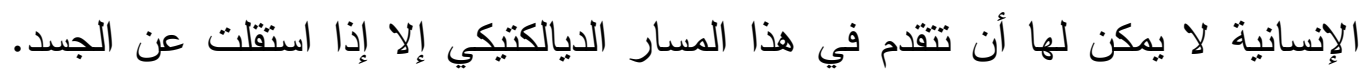

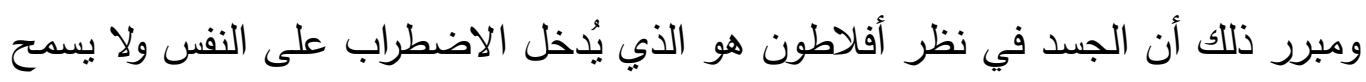

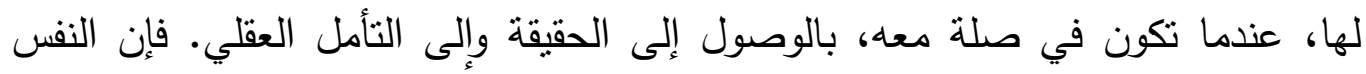

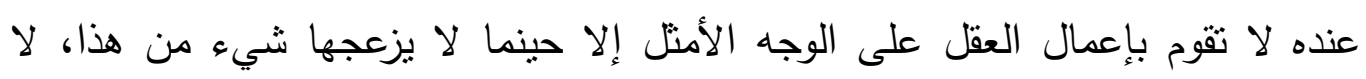

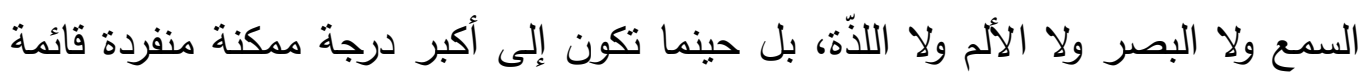

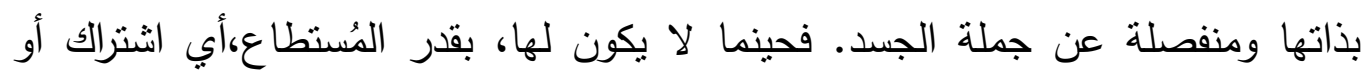


ارتباط معه فإنها تستطيع النطلع إلى الوجود الحقيقي وإدراكه. وبناءًا على ذلك فإنه كلما استقلت النفس عن الجسد بحواسه ولذّاته وآلمه، كلما كانت أكثر قدرة على الاقتراب،

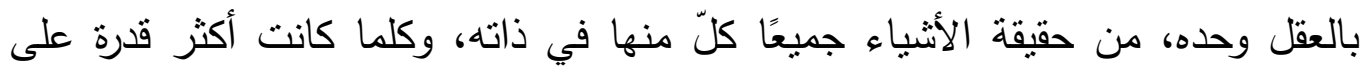

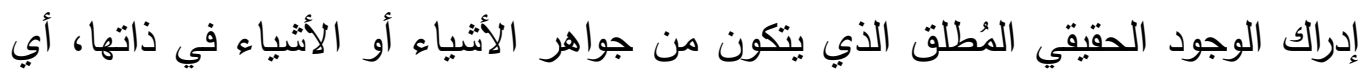

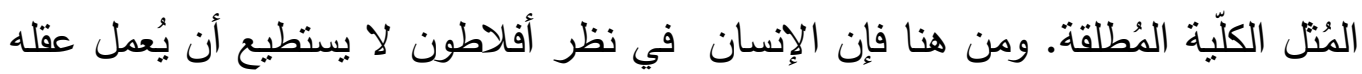
على التقدم في الدسار الديالكتيكي، الذي هو الطريق الوحيد إلى تحقيق المعرفة اليقينية،

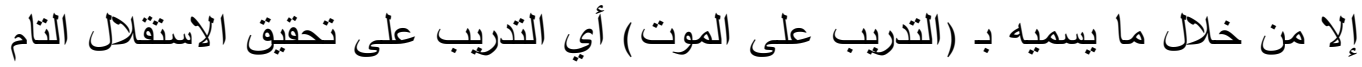

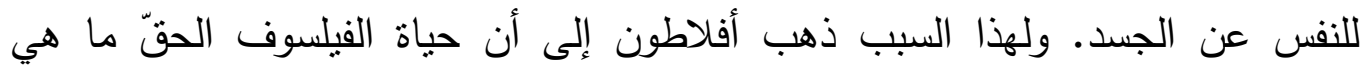

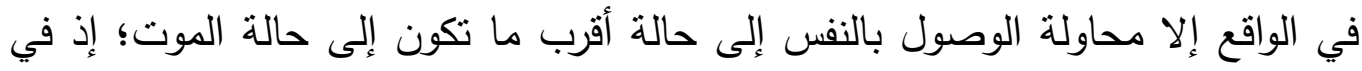

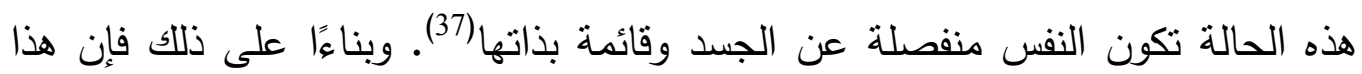
التدريب على الموت أو التدريب على استقلال النفس عن الجسد هو وحده الذي يُّكّن

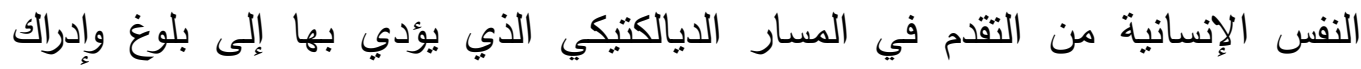

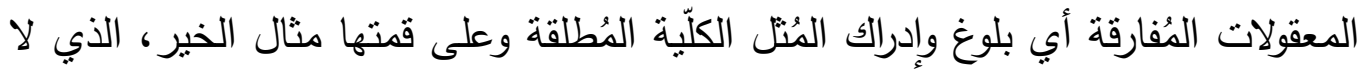

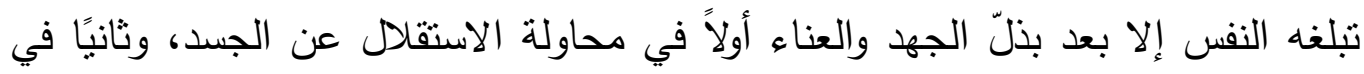

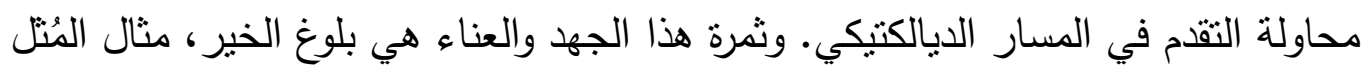

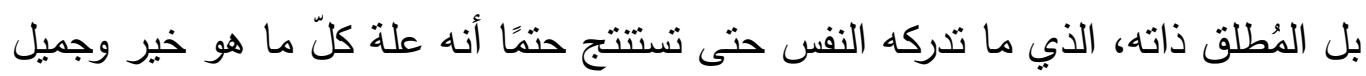
في الأثياء جميعًا بل ومصدر وجودها وحقيقتها أيضًا (38).

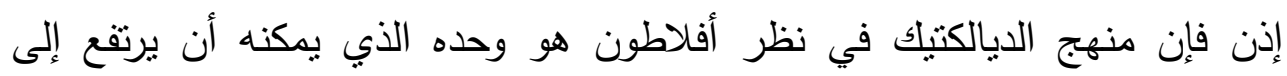

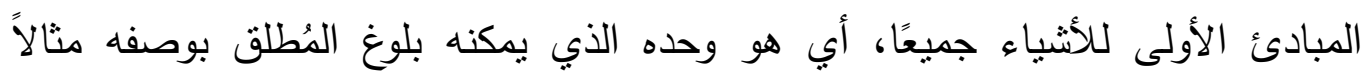

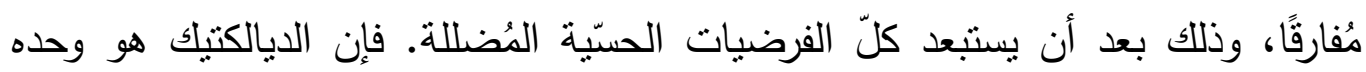

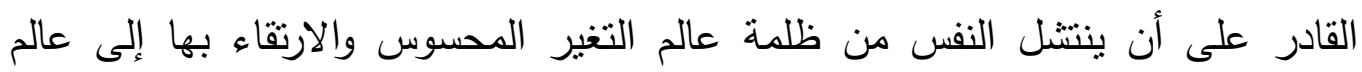

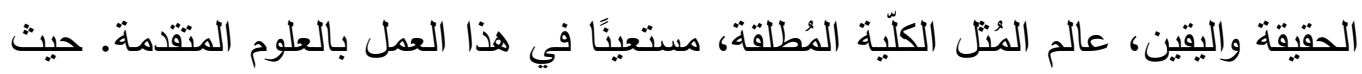


ذهب أفلاطون إلى أن دراسة علوم متل الحساب والهندة والفلك والموسيقى هو أمر لا بد منه كمرحلة تمهيدية لتعلُم الديالكتيك. فعلى الرغم من أن هذه العلوم تبدأ من الأنثياء

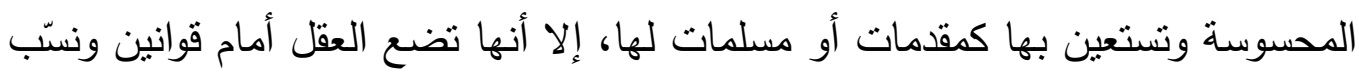

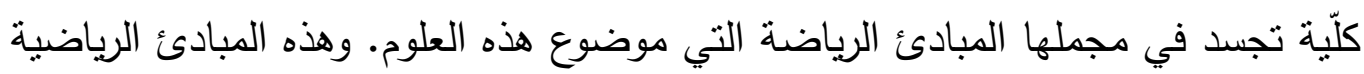

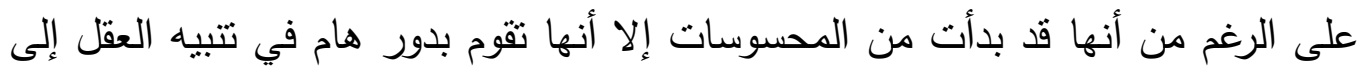

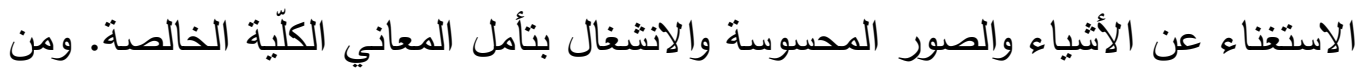

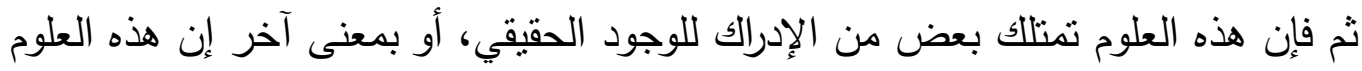

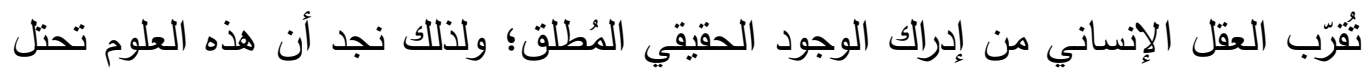

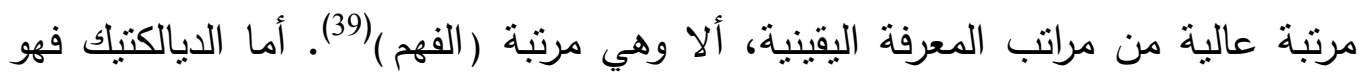

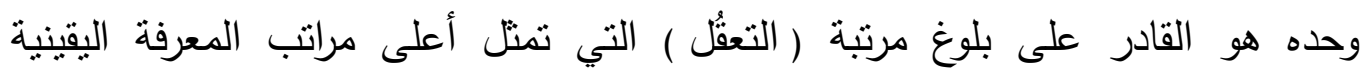

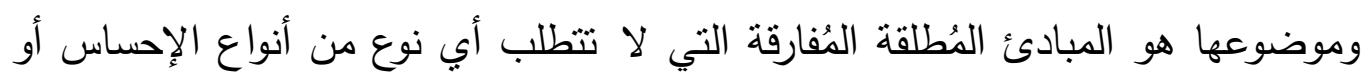

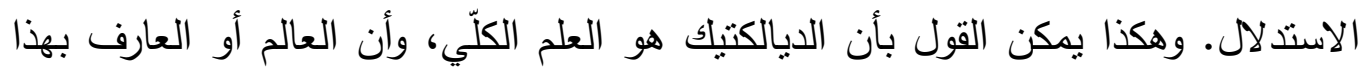

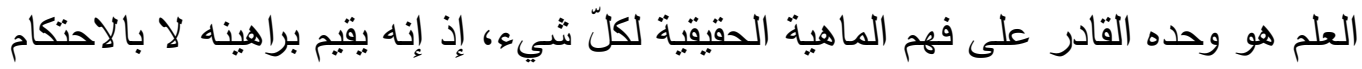

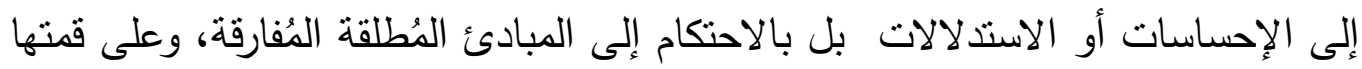

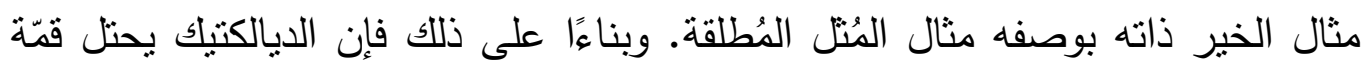

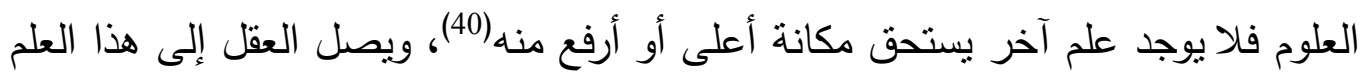

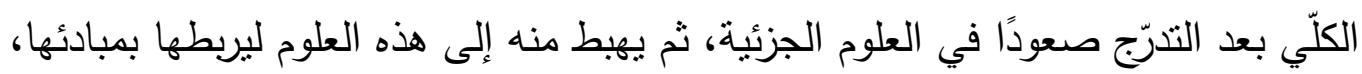

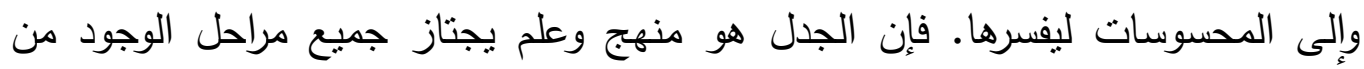
أسفل إلى أعلى والعكس. ومن حيث هو علم فهو يقابل ما نسميه الآن نظرية المعرفة بمعنى واسع يشمل كلّ من المنطق والمينافيزيقا معًا (41).

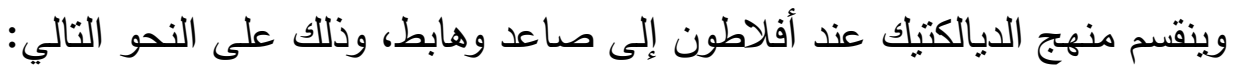

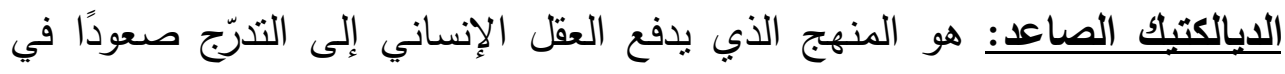

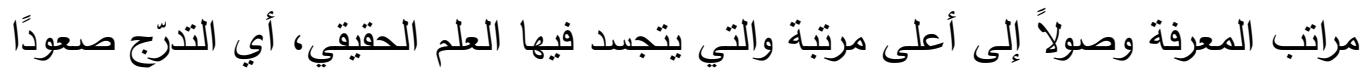


من الوهم إلى الظن، ثم من الظن إلى الفهم، وأخيرًا من الفهم إلى التعقُل المصض. أمـا

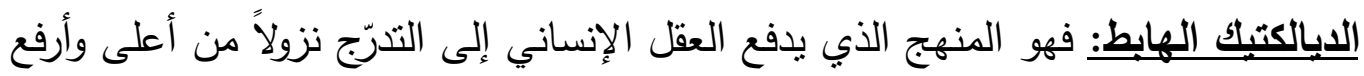

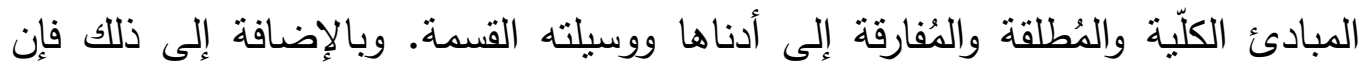

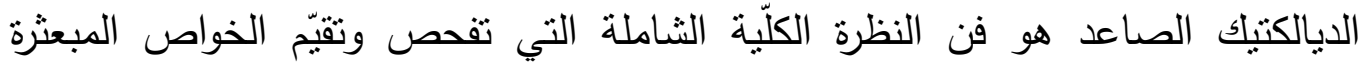

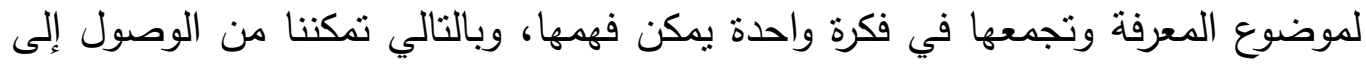

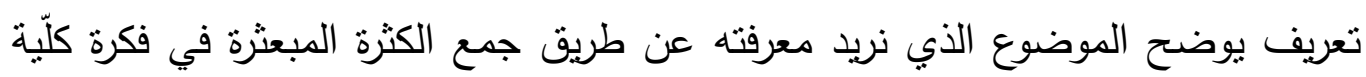
واحدة. أما الديالكتيك الهابط، على العكس من ذللك، فهو الفن الذي يمكننا من تقسيم

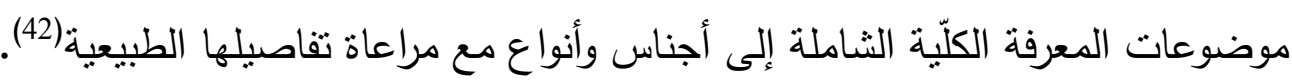

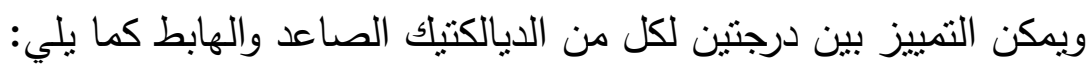

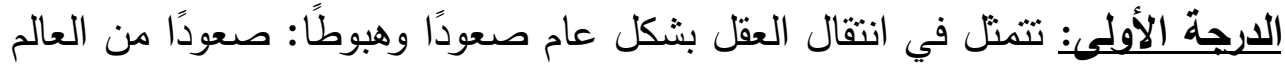

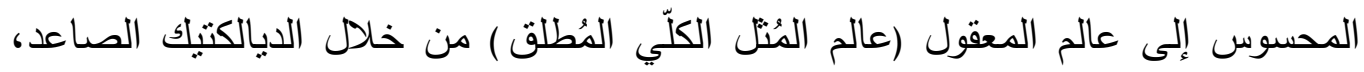

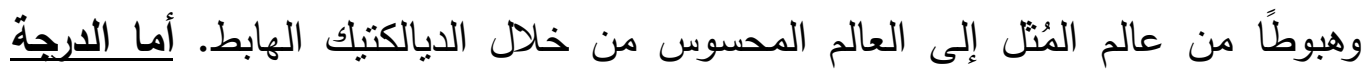

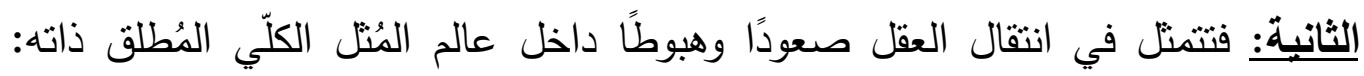

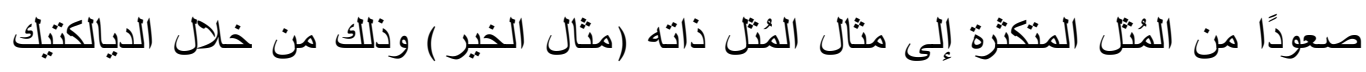

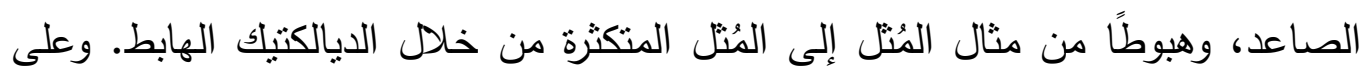

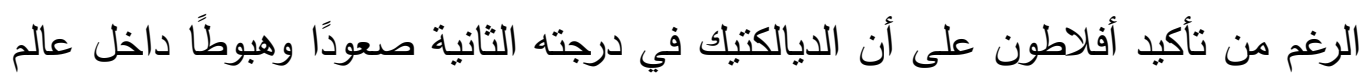
المُتلك هو الذي يمتل الدرجة الأرقى من الجدل العقلي، إذ من خلالده يبلغ العقل الإنساني

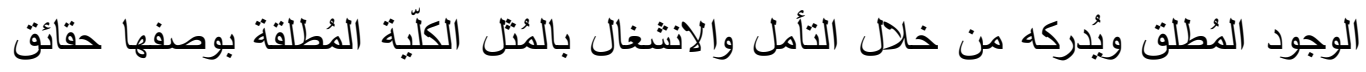

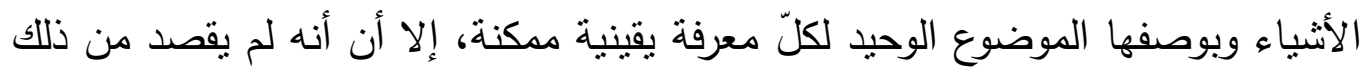

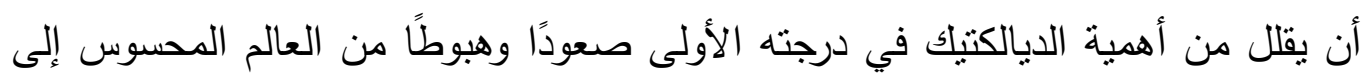

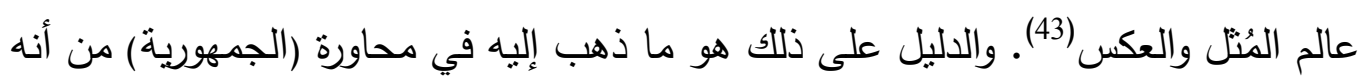

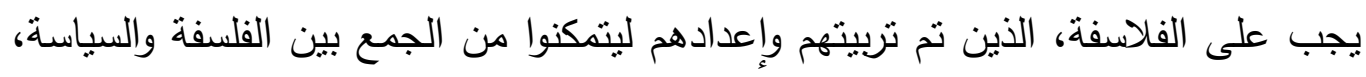

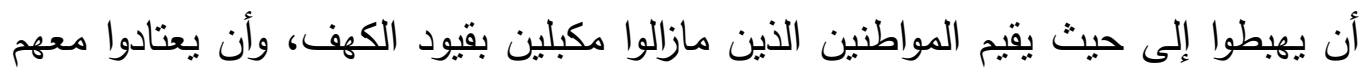


على رؤية الظلال. وذلك لأنهم أثناء اكتسابهم لتلك العادة، سوف برون عشرة آلاف مرة

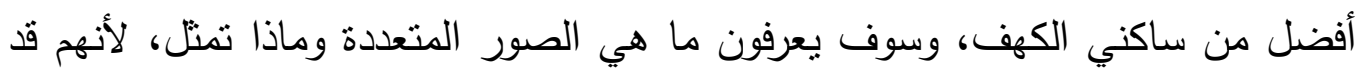

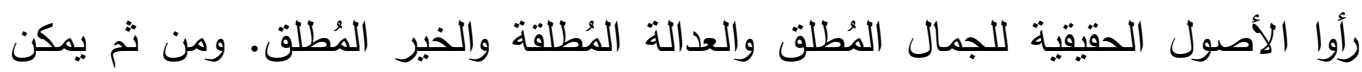

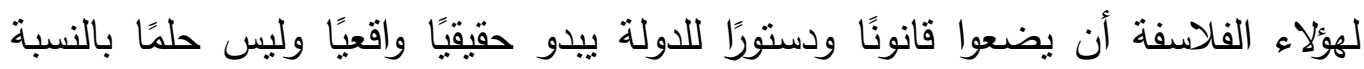
لجميع المواطنين(44). إذن فالنتيجة النهائية من كل ذلك إنه لا يمكن تحقيق المعرفة اليقينية والعلم الحقيقي

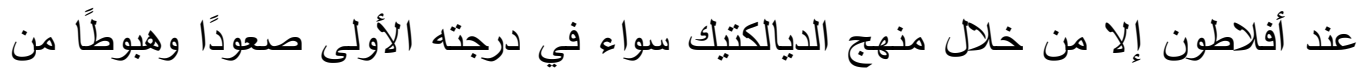

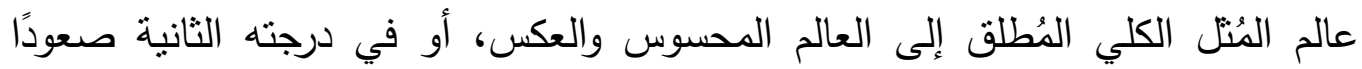

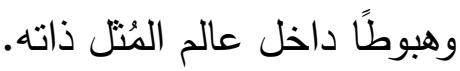
ويمكن تبرير ما ذهب إليه أفلاطون من تقسيم منهج الديالكتيك إلى صاعد وهابط من

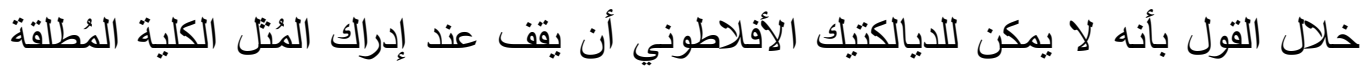

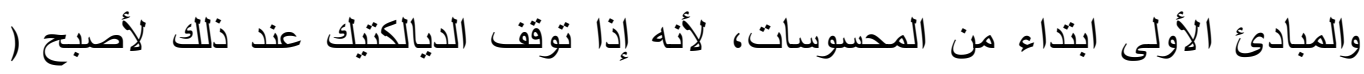

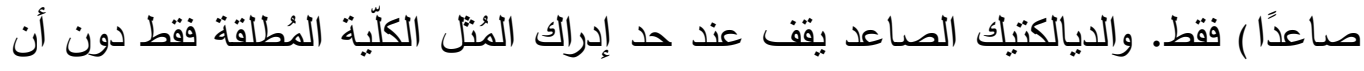
يحكم عليها، في حين أن العلم الحقيقي يقوم في الحكم. والحكم هنا يعنى أن شيئًا ما (

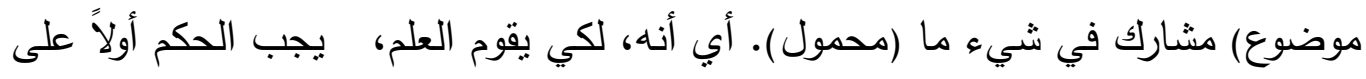

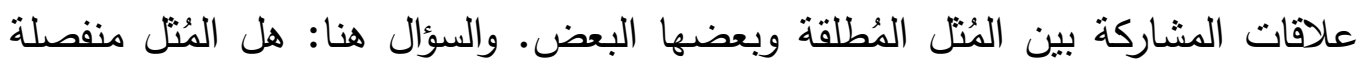

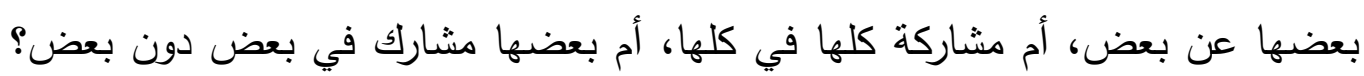

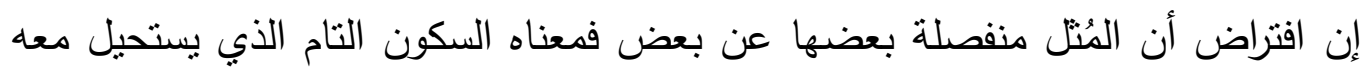

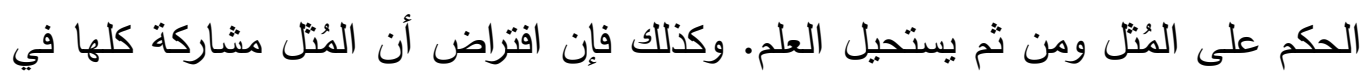
كلها معناه السيلان والتغير الدائم الذي يستحيل معه الدكم على الدُّتل ومن ثم يستحيل

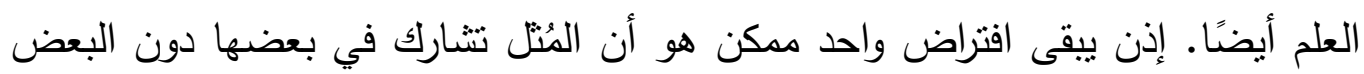

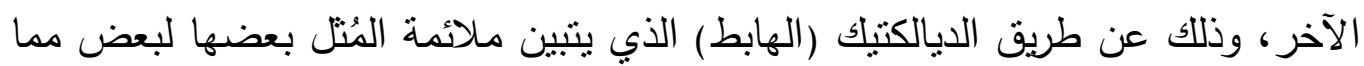


يجعل الحكم عليها ممكنًا، ومن ثم يجعل العلم ممكنًا. فإن الديالكتيك الهابط هو الذي

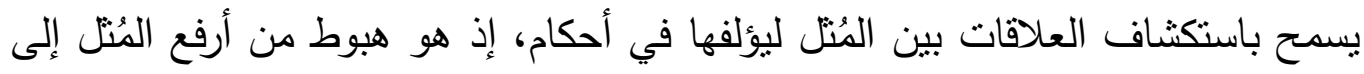

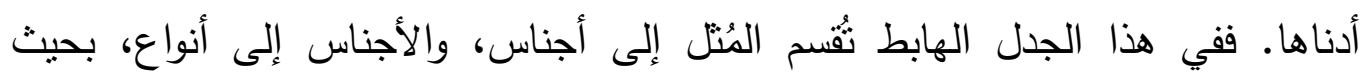

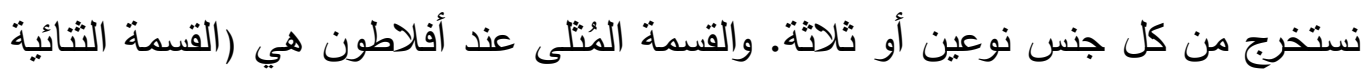

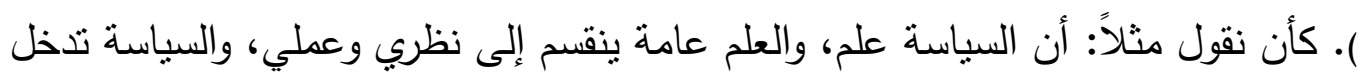

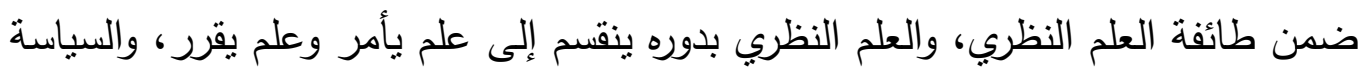

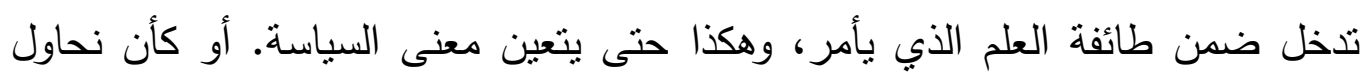

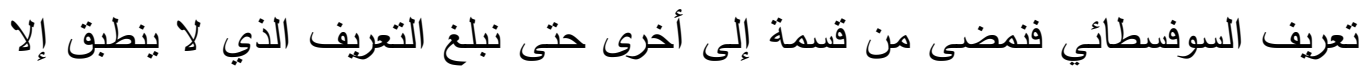

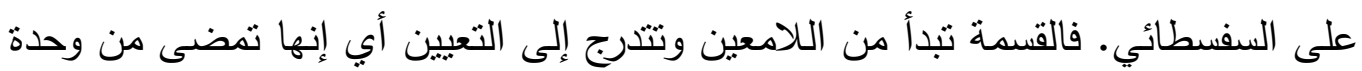

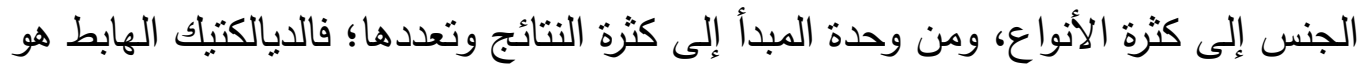

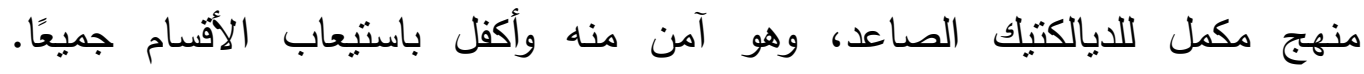

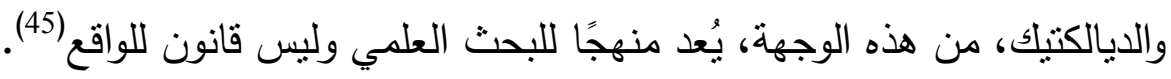

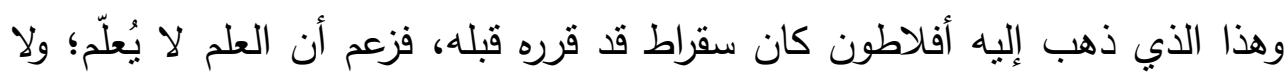

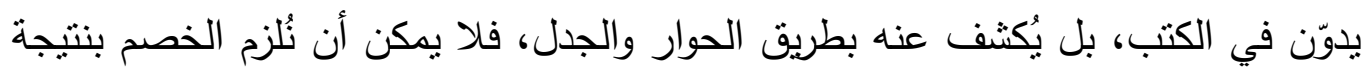

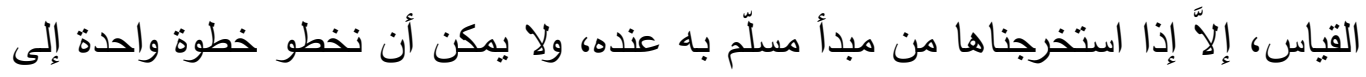

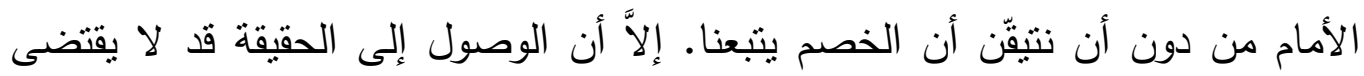

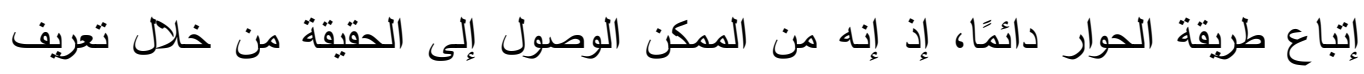

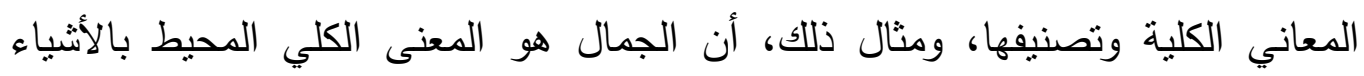

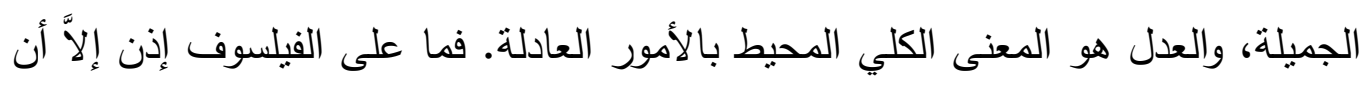

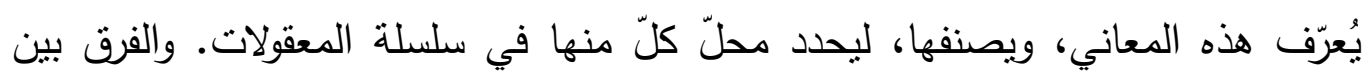

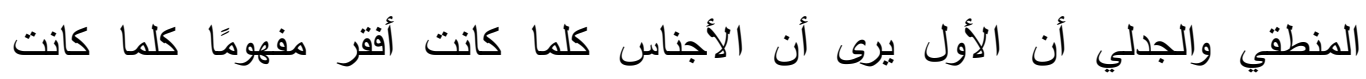

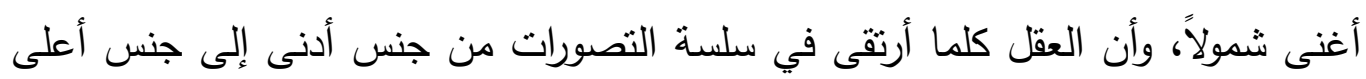


كلما أفقر المفهوم وأغنى الماصدق، وهكذا حتى يصل إلى أعلى الأجناس وأقلها تعينًا.

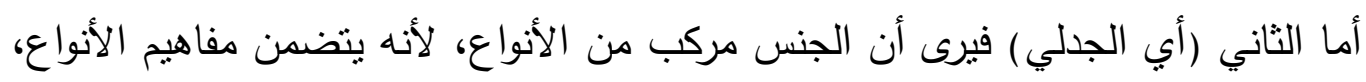

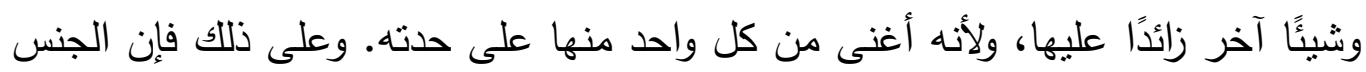

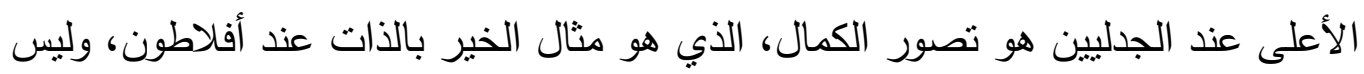

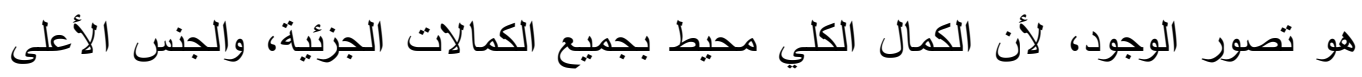

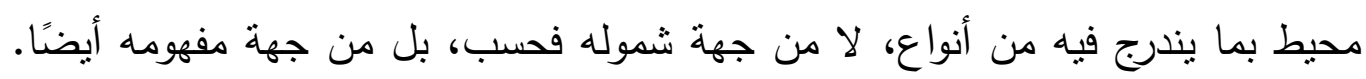

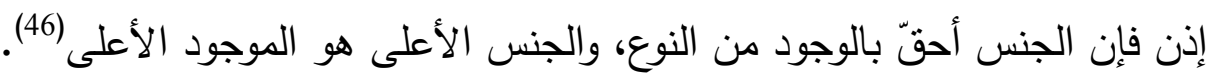

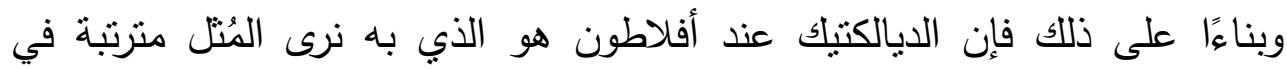

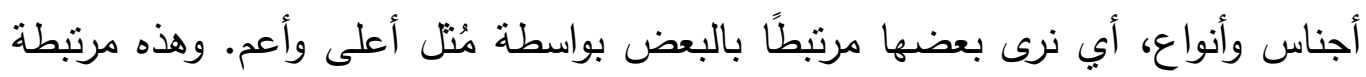

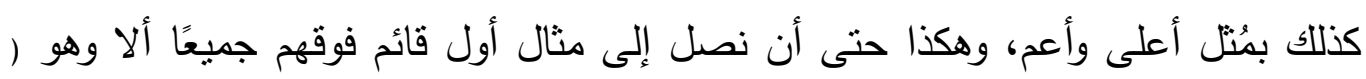

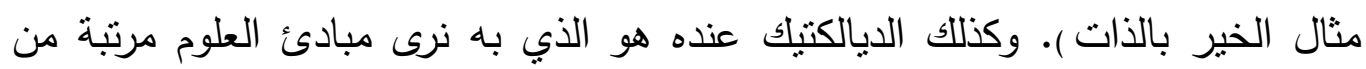
الأخص إلى الأعم حتى نصل إلى مبدأين أساسيين هما:

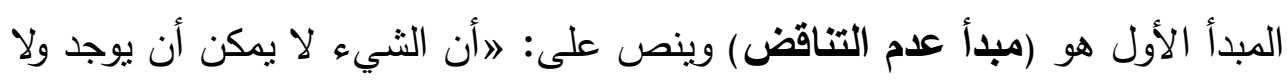

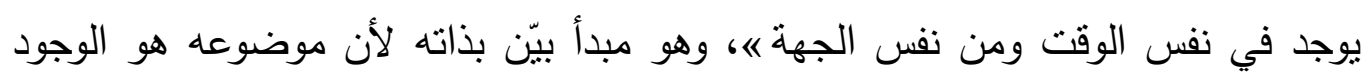

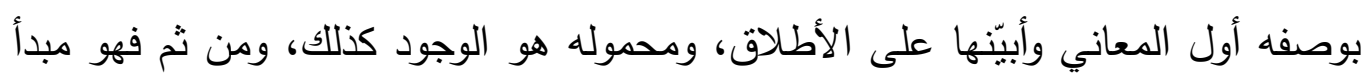

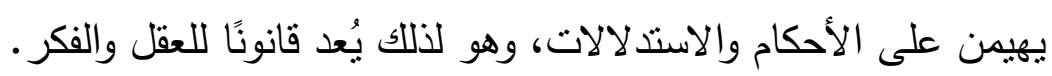

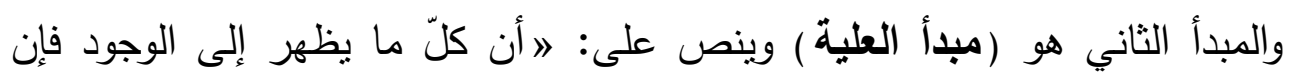

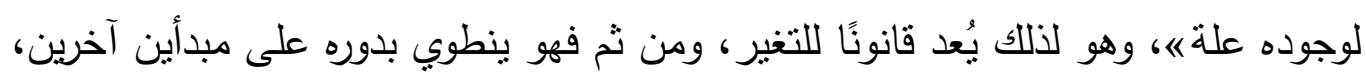

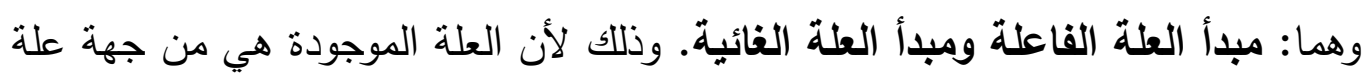

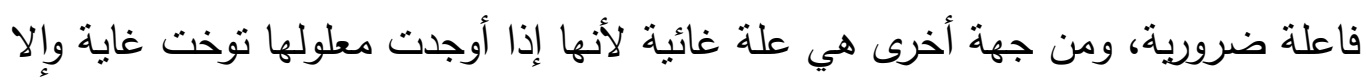
لما كانت خرجت عن سكونها. 


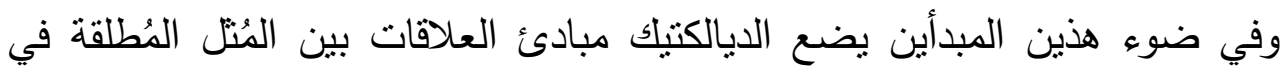

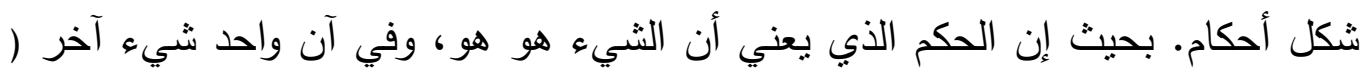

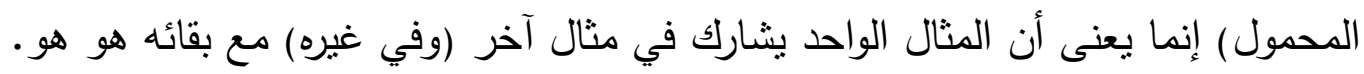

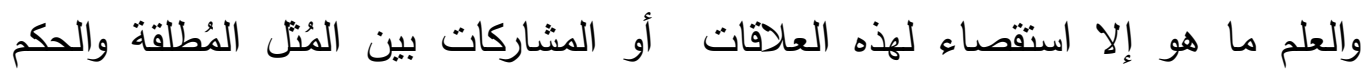
عليها (47).

وإحراز هذا العلم في رأى أفلاطون هو المشكلة الرئيسية في الفلسفة. فإن معرفة كلّ الكّل

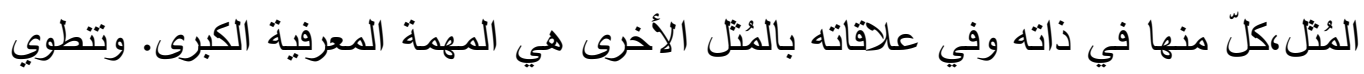

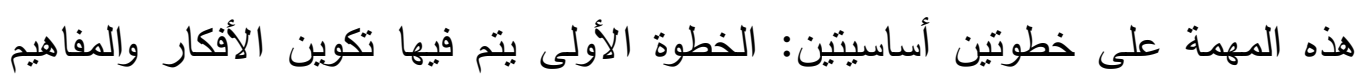

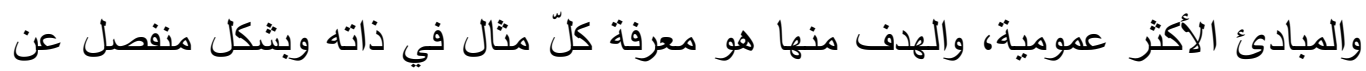

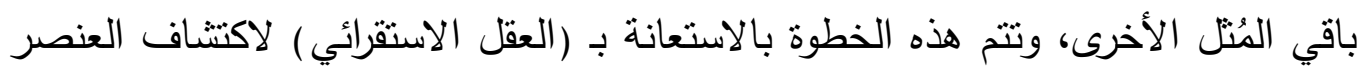

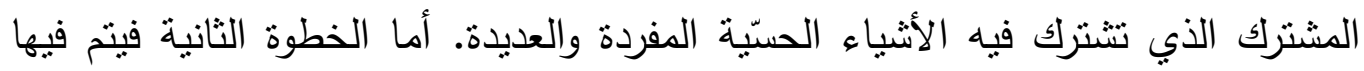

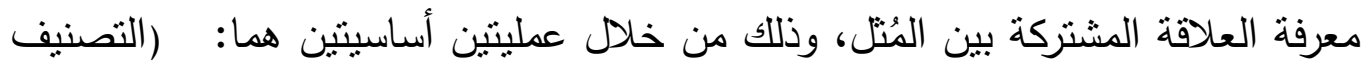
أو التبويب) و (التقسيم أو التشعيب). وعلى الرغم من أنه في كلتا هاتين العطليتين يتم

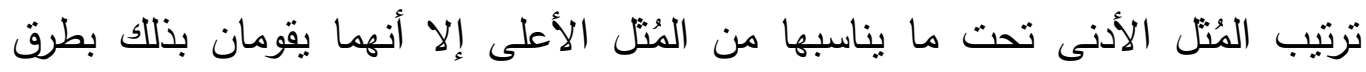

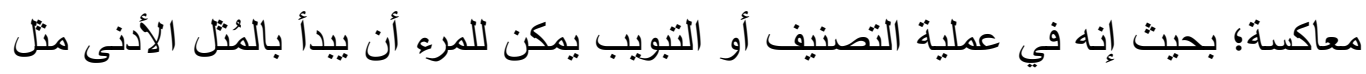

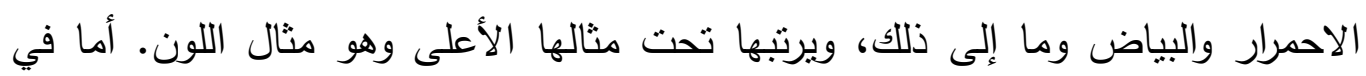

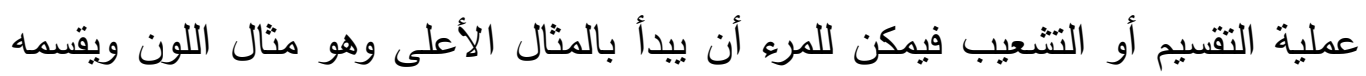

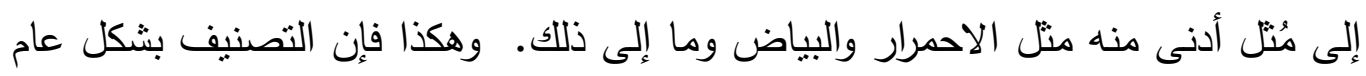

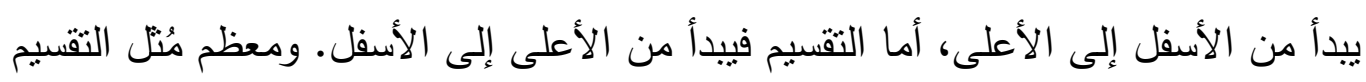

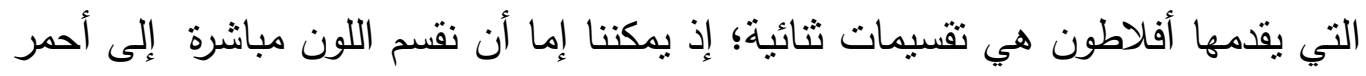

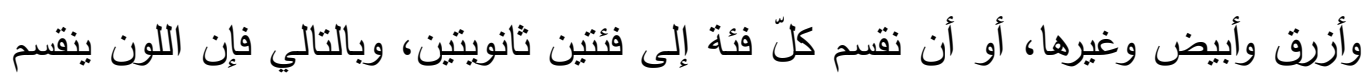

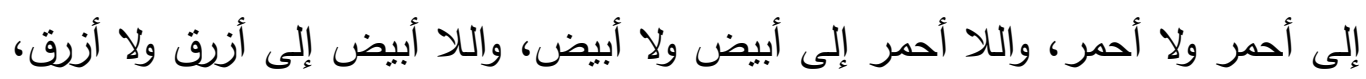


وهكذا. وهذه هي عملية القسمة الثنائية التي تمت الإثنارة إليها سابقًا باعتبارها القسمة

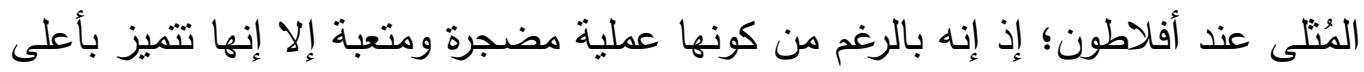
درجات الدقّة والتتظيم والثمول (48). وعلى الرغم من أن عمليتي التصنيف والتقسيم هما المهمة الكبرى للايالكتيك إلا أن

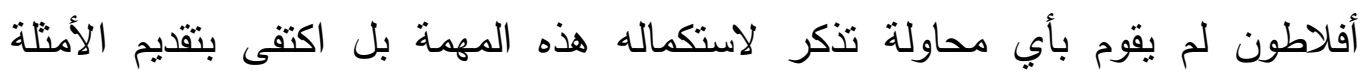

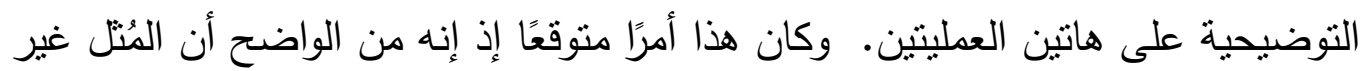
قابلة للحصر فهي غير متتاهية من حيث العدد، وبالتالي فإن مهمة تصنيفها وترتيبها

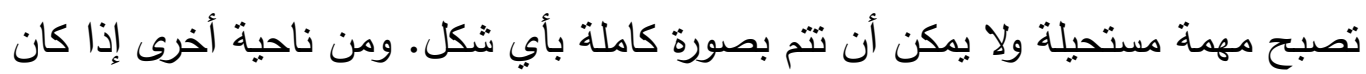

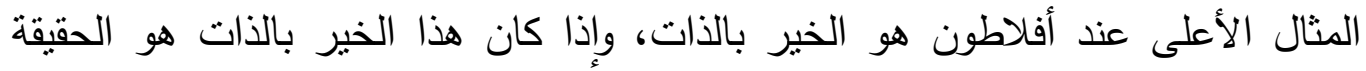

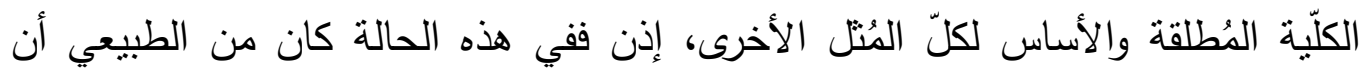

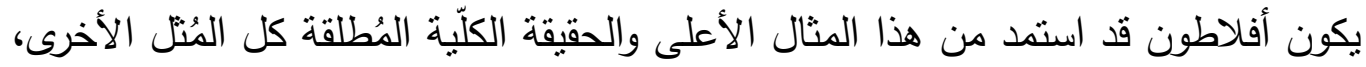

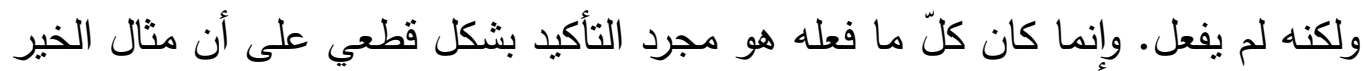
بالذات هو المثال الأقصى، وذلك دون أن يفعل شينًا ليربطه بالمُتل الأخرى أو يستمدها

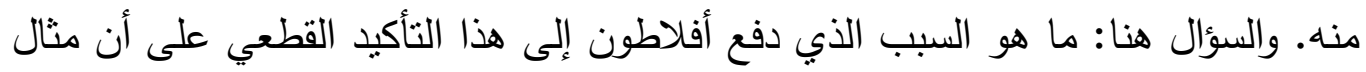

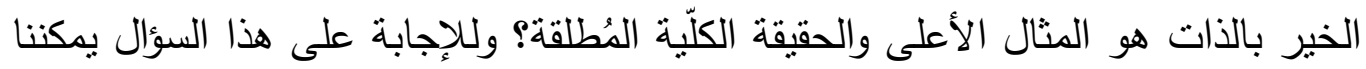

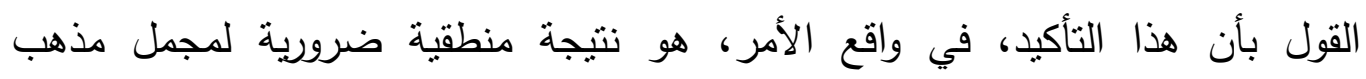

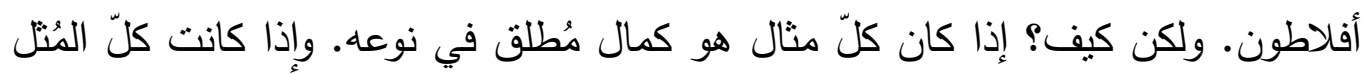

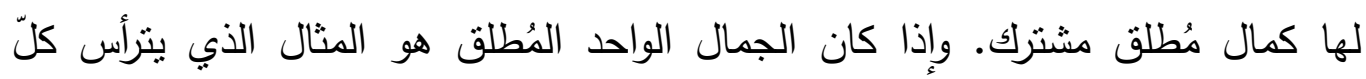

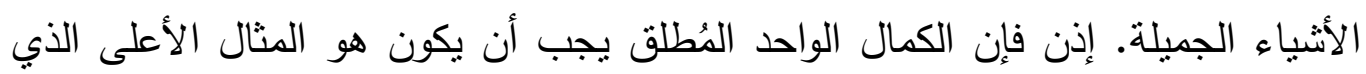

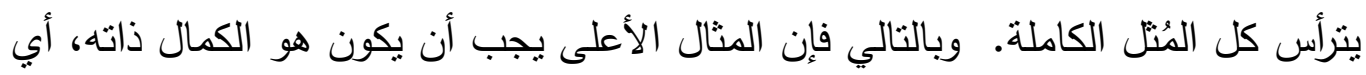

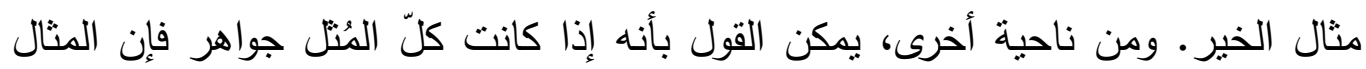
الأعلى هو مثال الجوهر ذاته، أي مثال الخير (49). 
وبإمعان النظر في مثال الخير بالذات، وما يندرج تحته من مُنل عديدة، يمكن تبيّن

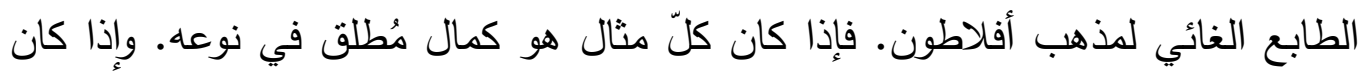

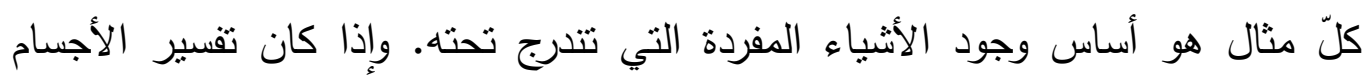

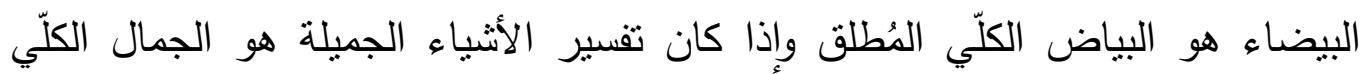

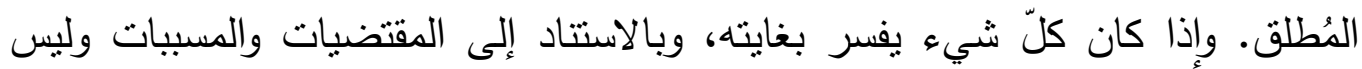
بالاستتاد إلى العلل الآلية. إذن فإن النتيجة المنطقية من كلّ ذلك أن كلّ مثال إنما يجسد،

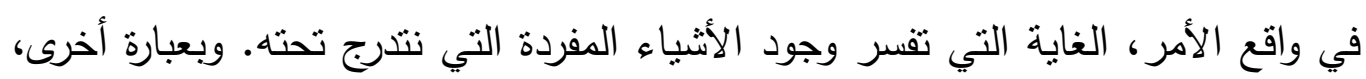

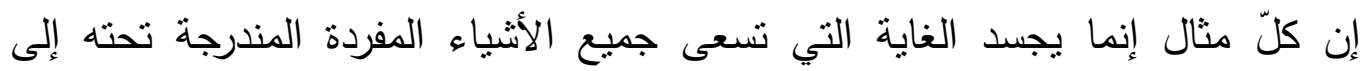

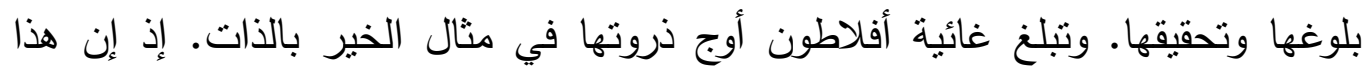

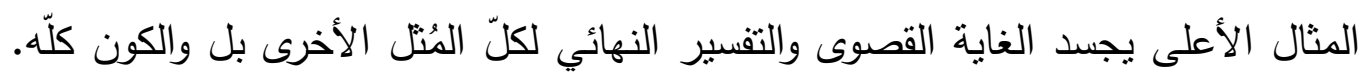

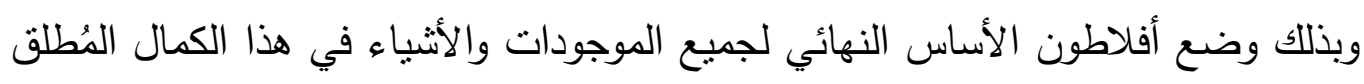

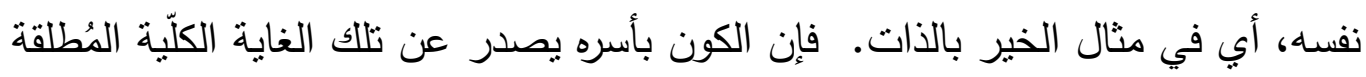
التي تتحرك نحوها الأشياء جميعًا (50). وهكذا فإذا كان منهج الجدل هو الوسيلة الوحيدة التي بها يبلغ الإنسان هذه الغاية التهاية

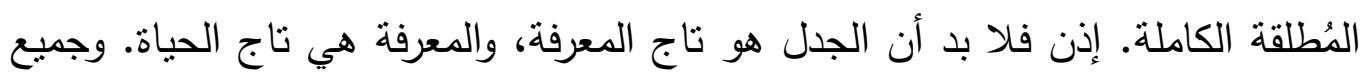

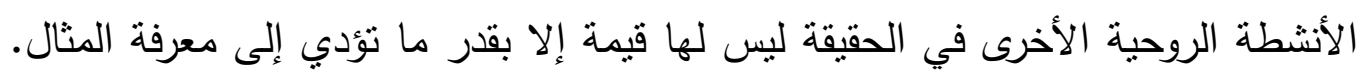

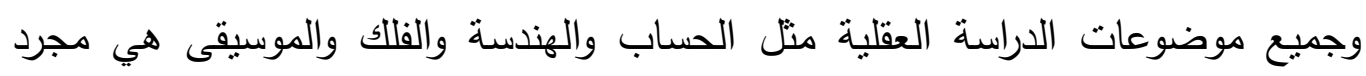
استعداد لدراسة الفلسفة؛ إذ إن هذه العلوم الخاصة في نظر أفلاطون ليست لهات لها قيمة في

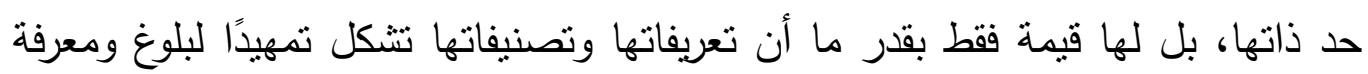

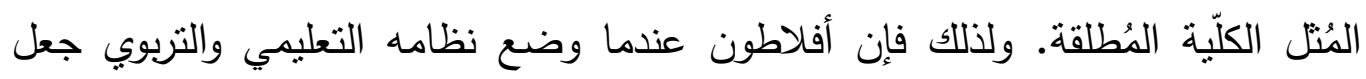

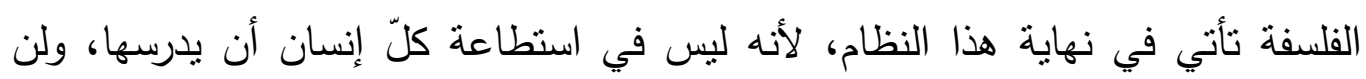

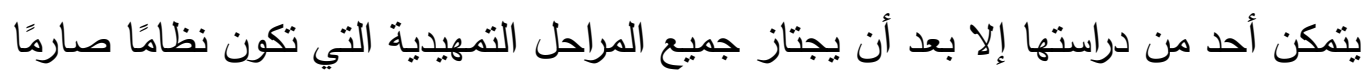


للعقل قبل أن بدخل أخيرًا إلى الجدل. وهكذا فإن كلّ معرفة عند أفلاطون إنما نتتهى إلى

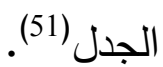

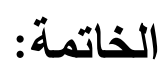

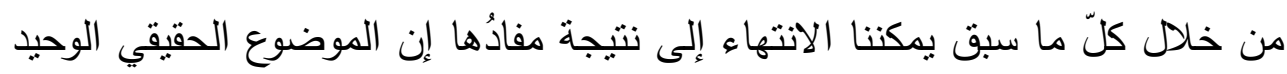

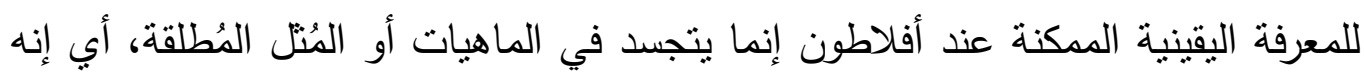

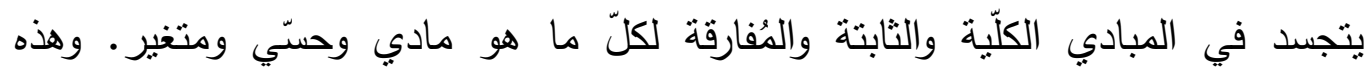

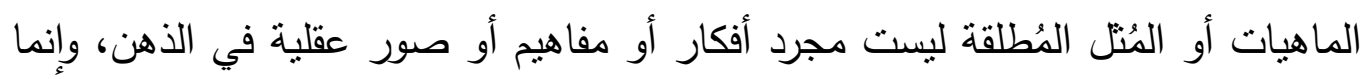

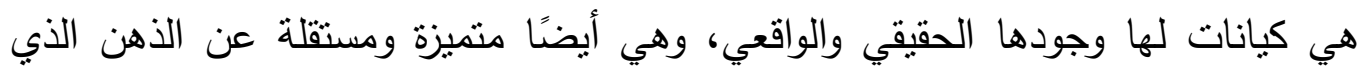

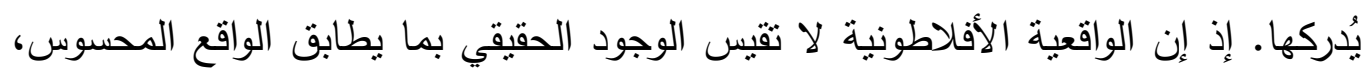

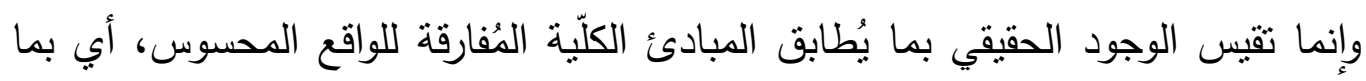

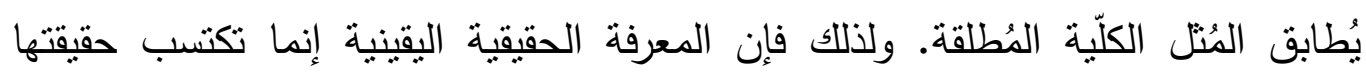
ويقينيتها من حقيقية ويقينية موضوعها، أي من حقيقة وواقعية المُتل ذاتها.

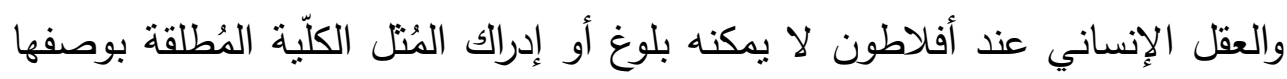

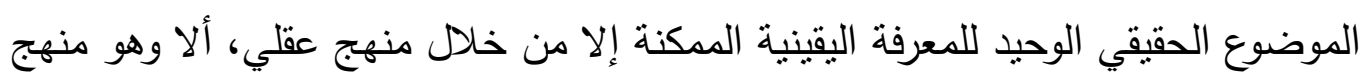

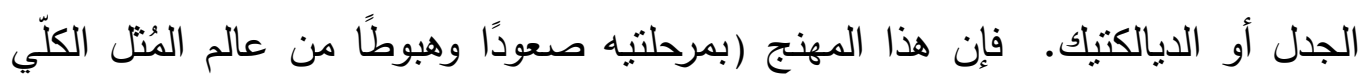

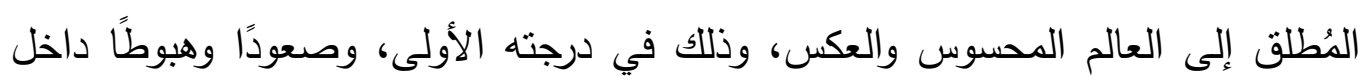

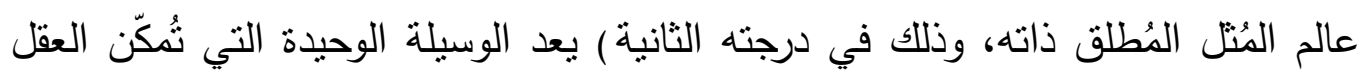

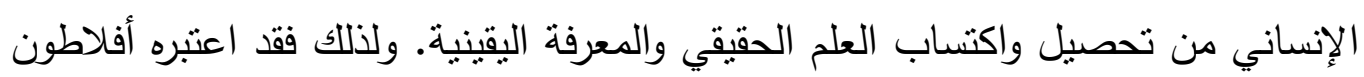
العلم الأعلى الذي لا يوجد علم آخر يستحق مكانة أعلى أو أرفع منه. 


\section{المصادر والمراجع والهوامش \\ حسب ورودها في متن البحث}

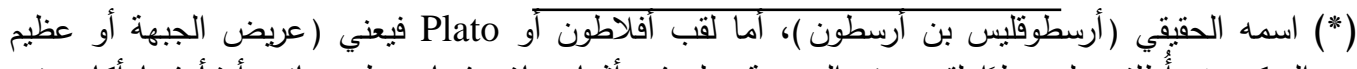

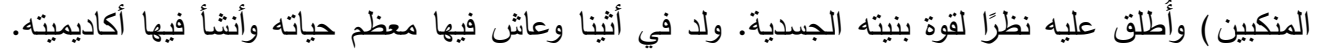

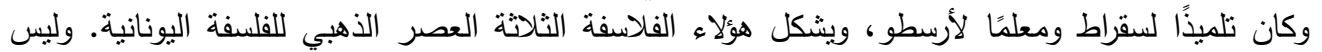

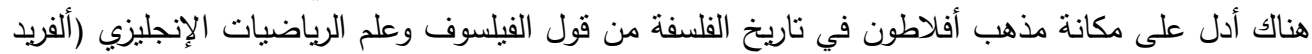

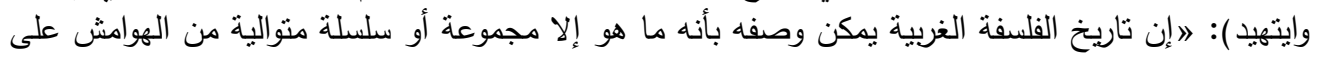

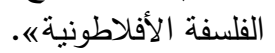

Look: Whitehead, Alfred North: Process And Reality, An Essay In Cosmology, Gifford Lectures Delivered In The University Of Edinburgh During The Session 1927-28, Corrected Edition, Edited By David Ray Griffin And Donald W. Sherburne, The Free Press, A Division Of Macmillan Publishing CO., INC., New York, 1978. Part: II, Chapter: I, Section: I, P: 39.

Look Too: Laertius, Diogenes: The Lives and Opinions of Eminent Philosophers, Literally Translated by C. D. Yonge, M. A., London, George Bell \& Sons, 1895. Book: III, P-P: 113-151.

(1) Copleston, Frederick Charles, S. J: A History of Philosophy, Volume: 1, Greece And Rome, Burns \& Oates, 1946. Part: III, Chapter: XIX, P: 143.

(2) Ibid, Part: III, Chapter: XIX, P, P: 149, 150.

(3) Plato: Theaetetus, Translated into English with Analyses and Introductions By Benjamin Jowett, M. A. in "Dialogues of Plato" Volume: III, New York, Charles Scribner's Sons, 1899. Paragraphs: 158-186, P-P: 358-390.

(4) Ibid, Paragraphs: 187-210, P-P: 390-419.

(5) Plato: The Republic, Translated into English with Analyses and Introductions By Benjamin Jowett, M. A. in "Dialogues of Plato" Volume: II, New York, Charles Scribner's Sons, 1899. Book: VI, Paragraphs: 510, 511, P, P: 338, 339.

(6) Copleston, Frederick Charles, S. J: A History of Philosophy, Op.cit, Part: III, Chapter: XIX, P, P: 150, 151.

(7) Ibid, Part: III, Chapter: XIX, P, P: 151, 152.

Look Too: Borchert, Donald M: Encyclopedia of Philosophy, Second Edition, Macmillan Reference USA, Thomson Gale, London \& New York, 2006.Vol: 4, P: 553.

وأنظر أيضًا: المعجم الفلسفي، إبراهيم مدكور، مجمع اللغة العربية، الهيئة العامة لثئون المطابع الأمبرية،

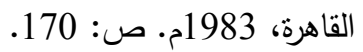


(8) Copleston, Frederick Charles, S. J: A History of Philosophy, Op.cit, Part: III, Chapter: XIX, P, P: 152, 153.

(9) Plato: The Republic, Op.cit, Book: VI, Paragraphs: 509-511, P-P: 337-340.

(10) Ibid, Book: VI, Paragraphs: 507, 508, P-P: 334-336.

(11) Ibid, Book: VI, Paragraph: 509, P, P: 336, 337.

(12) Ibid, Book: VII, Paragraphs: 514, 515, P, P: 341, 342.

(13) Murphy, Neville Richard: The Interpretation of Plato's Republic, At the Clarendon Press, Oxford, 1960. P: 156.

(14) فؤاد زكريا، جمهورية أفلاطون، الدراسة، دار الوفاء لدنيا الطباعة والنشر، الأسكندرية، 2004م. ص، ص: .153، 152

$$
\text { المرجع السابق، ص، ص: 145، } 146 .
$$

(16) Havelock, Eric Alfred: Preface to Plato, The Belknap Press of Harvard University Press, London, 1963. Part: Two. Chapter: XIV, P-P: 262-264.

$$
\text { (17) فؤاد زكريا، جمهورية أفلاطون، الدراسة، ص- ص: 147-150. }
$$

(18) Taylor, Alfred Edward: The Mind of Plato, Ann Arbor Paperbacks, The University of Michigan Press, First American Edition, 1960. Chapter: II, P, P: 43, 44.

(19) مصطفى النشار، ناريخ الفلفة اليونانية من منظور شرقي، الجزء الثاني، السوفسطائيون، سقراط، أفلاطون،

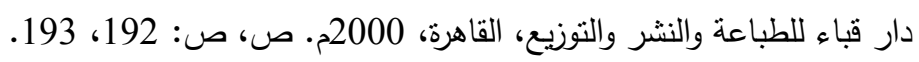

(20) مراد وهبة، المعجم الفلسفي، الهيئة المصرية العامة للكتاب، الطبعة السادسة، القاهرة، مكتبة الأسرة،

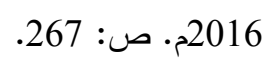

(21) مراد وهبة، قصة الديالكتيك، دار العالم الثالث، الطبعة الأولى، القاهرة، 1997م. ص: 5.

(22) الجرجاني، معجم التعريفات، تحقيق ودراسة: محمد صديق المنشاوي، دار الفضيلة للنشر والتوزيع والتصدير ،

$$
\text { بدون تاريخ للنشر • ص: }
$$

(23) أندريه لالاند، الموسوعة الفلسفية، تعريب خليل أحمد خليل، منشورات عويدات، بيروت- باريس، الطبعة

$$
\text { الثانية، 2001م. ص: } 272 .
$$


(24) إمام عبد الفتاح إمام، نطور الجدل بعد هيجل، الكتاب الأول، جدل الفكر، دار التتوير للطباعة والنشر

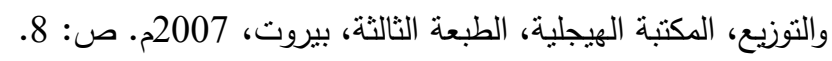

(25) Plato: Parmenides, Translated into English with Analyses and Introductions By Benjamin Jowett, M. A. in "Dialogues of Plato" Volume: III, New York, Charles Scribner's Sons, 1899. Paragraph: 128, P: 245.

(26) Freeman, Kathleen: Ancilla to the Pre-Socratic Philosophers, A Complete Translation of The Fragments in Diels, Fragmente der Vorsokratiker, Harvard University Press, 1948. Gorgias Fragments: 1-3, P-P: 127-129.

(27) Plato: The Republic, Op.cit, Book: I, Paragraph: 337, P: 158.

$$
\text { (28) مراد وهبة، قصة الديالكتيك، ص- ص: 6-9. }
$$

(29) Plato: Phaedo, Translated into English with Analyses and Introductions By Benjamin Jowett, M. A. in "Dialogues of Plato" Volume: I, New York, Charles Scribner's Sons, 1899. Paragraphs: 75, 76, P-P: 402-404.

(30) Plato: Phaedrus, Translated into English with Analyses and Introductions By Benjamin Jowett, M. A. in "Dialogues of Plato" Volume: I, New York, Charles Scribner's Sons, 1899. Paragraphs: 247, 248, P, P: 552, 553.

(31) أحمد فؤاد الأهواني، معاني الفلسفة، دار إحباء الكتب العربية، الطبعة الأولى، القاهرة، 1947م. ص- ص: صل .122-120

(32) Plato: Cratylus, Translated into English with Analyses and Introductions By Benjamin Jowett, M. A. in "Dialogues of Plato" Volume: I, New York, Charles Scribner's Sons, 1899. Paragraph: 390, P: 629.

(33) Zeller, Eduard: Outlines of the History of Greek Philosophy, Thirteenth Edition, Revised by Wilhelm Nestle, and Translated by L. R. Palmer, Routledge \& Kegan Paul Limited, London, 1948. Second Period, Chapter: III, 36, P: 129.

$$
\text { (34) أندريه لالاند، موسوعة لالاند الفلسفية، المجلد الأول، ص: } 273 .
$$

(35) Plato: The Republic, Op.cit, Book: VI, Paragraph: 511, P: 339.

(36) Ibid, Book: VII, Paragraph: 532, P, P: 359, 360.

(37) Plato: Phaedo, Op.cit, Paragraphs: 64-67, P-P: 389-393.

(38) Plato: The Republic, Op.cit, Book: VII, Paragraph: 517, P: 344.

(39) Ibid, Book: VII, Paragraphs: 521-533, P-P: 348-361. 
(40) Ibid, Book: VII, Paragraph: 534, P: 362.

(41) يوسف كرم، ناريخ الفلسة اليونانية، مطبعة لجنة التأليف والترجمة والنشر ، القاهرة، 1936م. ص: 84.

(42) Plato: Phaedrus, Op.cit, Paragraphs: 265, 266, P: 571.

$$
\text { مصطفى النشار ، تاريخ الفلسفة اليونانية من منظور شرقي، الجزء الثاني، ص: } 194 .
$$

(44) Plato: The Republic, Op.cit, Book: VII, Paragraph: 520, P: 347.

(45) يوسف كرم، تاريخ الفلسفة اليونانية، ص- ص: 94-96.

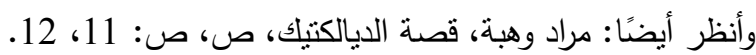

(46) جميل صليبا، المعجم الفلسفي، الجزء الأول، دار الكتاب اللبناني، بيروت - لبنان، 1982م. ص، ص: $.392 ، 391$

$$
\text { وأيضًا: مراد وهبة، كرم، تاريخ الفلسفة اليونانية، ص: } 94 \text { (47 الديالكتيك، ص: } 10 .
$$

(48) Stace, Walter Terence: A Critical History of Greek Philosophy, Macmillan And CO., Limited, ST. Martin's Street, London. 1920. Chapter: XII, P, P: 199, 200.

(49) Ibid, Chapter: XII, P, P: 200, 201.

(50) Ibid, Chapter: XII, P, P: 201, 202.

(51) Ibid, Chapter: XII, P: 204. 